\title{
Synthesis, characterization and antiviral evaluation of 1,3-Thiazolidine-4-one derivatives bearing L-Valine side chain
}

\author{
Esra Tatar1, İlkay Küçükgüzel1*, Erik De Clercq², Ramalingam Krishnan³, \\ Neerja Kaushik-Basu ${ }^{3}$
}

\begin{abstract}
Thiazolidine-4-ones have been known to possess anti-HIV and anti-HCV activity as they are, respectively, HIV-1 non-nucleoside reverse transcriptase inhibitors and HCV NS5B RNA-dependent RNA-polymerase inhibitors. Some novel 1-[2-(benzoylamino)3-methylbutyryl]-4-alkyl/arylalkylthiosemicarbazides, 2-[2-(benzoylamino)-3-methylbutyrylhydrazono]-3-alkyl-/arylalkyl- 5-non substituted/methyl-1,3-thiazolidinones, were synthesized and evaluated for their antiviral activity. Antiviral activity of the synthesized compounds were screened against various types of viruses (Feline Corona Virus (FIPV), Feline Herpes Virus, HSV-1(KOS), HSV-1(TK-KOS ACVr), HSV-2(G), Vaccinia virus, Vesicular stomatitis virus, VaricellaZosterVirus TK+VZV, Varicella-ZosterVirus TK-VZV, Cytomegalovirus, Respiratory syncytial virus, Coxsackie B4 virus, Parainfluenza-3 virus, Reovirus-1, Sindbis virus and Punta Toro virus) in CRFK, HEL, HeLa and Vero cell cultures. Anti-HIV and cytotoxicity data were also obtained with the compounds using the strains HIV-1 (III $\mathrm{B}_{\mathrm{B}}$ and HIV-2 (ROD) in an MT-4/MTT based assay. None of the tested compounds showed antiviral activity at subtoxic concentrations. For all the synthesized compounds anti-HCV NS5B RdRp activity was not observed at the concentration of $100 \mu \mathrm{M}$ which was the highest concentration tested.
\end{abstract}

KEYWORDS: 4-Thiazolidinones, L-valine, anti-HIV activity, anti-HCV activity.

\section{INTRODUCTION}

The 4-thiazolidinone ring system comprises a large number of biologically active compounds which have been evaluated as antibacterial (1-3), antitubercular (4-7), antifungal (8), antimalarial (9), or antiviral (10-23). Since infectious diseases are one of the leading causes of death worldwide (24) the infectious agents continue to evolve and adapt to existing therapies, via giving rise to resistance. Researchers have persisted in performing synthesis and biological evaluation of novel therapeutics.

AIDS (Acquired Immune Deficiency Syndrome) is one of the most spread and most deadly diseases in the modern era. According to the statistical data on the AIDS epidemic provided in 2010 by $\mathrm{WHO}$, there were 33.3 million people living with HIV, 2.6 million new HIV infections and 1.8 million AIDS-related deaths in 2009 (25). AIDS is the end-stage disease of HIV (human immunodeficiency virus) infection which was identified as a disease in 1981. HIV is a retrovirus which only replicates in certain human cells. With the aim of suppressing the infectivity, replication and virulence of HIV lots of new compounds were synthesized and among these compounds 25 of them have been licensed until 2008 (26). To infect its host cells, the retrovirus uses three essential enzymes: reverse transcriptase (RT), integrase (IN), protease (PR) (27). RT has been a major target for antiretroviral drug development and more than half of the currently approved drugs for the treatment of HIV-1 infection are RT inhibitors (28). There are five NNRTIs approved for clinical use: nevirapine, delavirdine, efavirenz, etravirine and rilpivirine (Figure 1). According to crystallographic studies of HIV-1 RT, the common binding mode of first-generation NNRTIs such as nevirapine and delavirdine could be defined as "butterfly-like" despite the chemical diversity of NNRTIs (29). The next-generation NNRTIs, diarylpyrimidine (DAPY) analogues such as etravirine and rilpivirine adopt different conforma-
AFFILIATIONS

1Marmara University Faculty of Pharmacy, Department of Pharmaceutical Chemistry, İstanbul, Turkey

2Katholieke Universiteit, Rega Institute for Medical Research, Leuven, Belgium 3UMDNJ-New Jersey Medical School, Department of Biochemistry and Molecular Biology, Newark, USA

CORRESPONDENCE İlkay Küçükgüzel

E-mail:

ikucukguzel@marmara.edu.tr Received:

15.03.2012

Revision:

13.042012

Accepted:

24.04.2012 
<smiles>O=C1Nc2cccnc2N(C2CC2)c2ncccc21</smiles>

Nevirapine<smiles>CC(C)Nc1cccnc1N1CCN(C(=O)c2cc3cc(NS(C)(=O)=O)ccc3[nH]2)CC1</smiles>

Delavirdine<smiles>O=C1Nc2ccc(Cl)cc2C(C#CC2CC2)(C(F)(F)F)O1</smiles>

Efavirenz<smiles>Cc1cc(C#N)cc(C)c1Oc1nc(Nc2ccc(C#N)cc2)nc(N)c1Br</smiles>

Etravirine<smiles>Cc1cc(/C=C/C#N)cc(C)c1Nc1ccnc(Nc2ccc(C#N)cc2)n1</smiles>

Rilpivirine

FIGURE 1. Structures of approved non-nucleoside reverse transcriptase inhibitors.

tional modes through their torsional flexibility and ability to reposition within the NNRTI binding pocket $(26,30-31)$. The resistance to NNRTIs following accumulation of two or more amino acid mutations as compared with the wild-type strain has led to the synthesis of new HIV-1 RT inhibitors bearing 1,3-thiazolidine-4-one core (Figure 2) (11-18). Therefore, we synthesized novel 1,3-thiazolidine-4-ones and studied their antiviral activity in accordance with our antiviral drug development attempt $(6,32-35)$.

Furthermore, 4-thiazolidinone derivatives have also been shown to exhibit anti-hepatitis $\mathrm{C}$ virus (HCV)activity as $\mathrm{HCV}$ NS5B polymerase inhibitors (20-21) and HCV NS5A inhibitors (Figure 2) (22-23). The therapeutic potential of the thiazolidinone scaffold against HCV NS5B employing 2',4'-difluoro4-hydroxybiphenyl-3-carboxylic acid [2-(5-nitro-2-furyl / substituted phenyl)-4-thiazolidinone-3-yl] amides were explored by Kaushik-Basu et.al (20). Of these evaluated derivatives the lead compound; 2',4'-difluoro-4-hydroxybiphenyl-3-carboxylic acid[2-(2-fluorophenyl)-4-thiazolidinone-3-yl]amide, which was previously synthesized by Küçükgüzel et al. (3), exhibited an $\mathrm{IC}_{50}$ value of 48 microM. Taken together, 1,3-thiazolidine4-ones synthesized in the present study were also assessed for their hepatitis C virus NS5B polymerase inhibitory activity.
Due to the fact of recurrent or persistent co-infections with the GB virus C (GBV-C), HBV, HCV, HSV-2 increases morbidity and mortality among $H I V$-infected individuals by the reason of increasing the HIV viral load (36-38), there is an urgent need for the treatment of these co-infections. The 4-thiazolidinone scaffold has not been shown to exhibit activity against Feline Corona Virus (FIPV), Feline Herpes Virus, HSV-1(KOS), HSV1(TK-KOS ACVr), HSV-2(G), Vaccinia virus, Vesicular stomatitis virus, Varicella-ZosterVirus $\mathrm{TK}^{+} V Z V$, Varicella-ZosterVirus $\mathrm{TK}^{-}$ $V Z V$, Cytomegalovirus, Vesicular stomatitis virus, Respiratory syncytial virus, Coxsackie B4 virus, Parainfluenza-3 virus, Reovirus-1, Sindbis virus, Coxsackie B4 virus, and Punta Toro virus yet. Since 4-thiazolidinone derivatives may be optimized for generating new analogues against the viruses mentioned above the antiviral activity of the synthesized 1,3-thiazolidine-4-ones were also studied against most of these viruses.

\section{EXPERIMENTAL}

\section{Chemistry}

All solvents and reagents were obtained from commercial sources and used without purification. All melting points $\left({ }^{\circ} \mathrm{C}\right.$, uncorrected) were determined using Kleinfeld SMP-II basic model melting point apparatus. Elemental analysis was obtained using Leco CHNS-932 and is consistent with the assigned structures. Infrared spectra were recorded on Schimad$\mathrm{zu}$ FTIR $8400 \mathrm{~S}$ and expressed in wavenumber $\left(\mathrm{cm}^{-1}\right)$. NMR 
<smiles>Cc1cccc(N2C(=O)CSC2c2c(Cl)cccc2Cl)n1</smiles>

$$
\mathrm{EC}_{50}\left(\mathrm{HIV}-1_{\text {IIIB }}\right)=0.044 \mu \mathrm{M}
$$

(Ref. 7)<smiles>Cc1cccc(N2C(=O)CSC2c2c(Cl)cccc2Cl)c1</smiles>

$\mathrm{EC}_{50}\left(\mathrm{HIV}-1_{\mathrm{IIIB}}\right)=0.080 \mu \mathrm{M}$

(Ref. 8)<smiles>Cc1cc(C)nc(N2C(=O)CSC2c2c(Cl)cccc2Cl)n1</smiles>

$\mathrm{EC}_{50}\left(\mathrm{HIV}-1_{\text {IIIB }}\right)=0.017 \mu \mathrm{M}$

(Ref. 9)<smiles>O=C(NN1C(=O)CSC1c1ccccc1F)c1cc(-c2ccc(F)cc2F)ccc1O</smiles>

$\mathrm{IC}_{50}$ (HCV NS5B RdRp inhibitor) $=48 \mu \mathrm{M}$

(Ref. 20)<smiles>CC(NC(=O)OCc1ccccc1)C(=O)Nc1ccc(C2S/C(=N/c3cccc(F)c3)N(Cc3ccco3)C2=O)cc1</smiles>

BMS-858

$\mathrm{EC}_{50}(\mathrm{HCV} \mathrm{NS5A})=0.57-1 \mu \mathrm{M}$

(Ref. 22)

FIGURE 2. New HIV-1 RT, HCV NS5B RdRp and HCV NS5A inhibitors bearing 1,3-thiazolidine-4-one core.

spectra were recorded on Bruker AVANCE-DPX 400 at 400 $\mathrm{MHz}$ for ${ }^{1} \mathrm{H}-\mathrm{NMR}$ and $100 \mathrm{MHz}$ for ${ }^{13} \mathrm{C}-\mathrm{NMR}$ (DEPT and Decoupled), the chemical shifts were expressed in $\delta$ (ppm) downfield from tetramethylsilane (TMS) using DMSO- $\mathrm{d}_{6}$ as solvent. The liquid chromatographic system consists of an Agilent technologies 1100 series instrument equipped with a quaternary solvent delivery system and a model Agilent series G1315 A photodiode array detector. A Rheodyne syringe loading sample injector with a $50 \mu \mathrm{l}$ sample loop was used for the injec- tion of the analytes. Chromatographic data were collected and processed using Agilent Chemstataion Plus software. The separation of compounds $\mathbf{3}$ and 4-18 were performed at ambient temperature by using a reversed phase Waters; $\mu$-Bondapak $\mathrm{CN}$ (RP) $(3.9$ x $150 \mathrm{~mm}, 10 \mu \mathrm{m}$ particle size) column. All experiments were employed in isocratic mode. The mobile phase was prepared by mixing acetonitrile and TEA-phosphate buffer $\mathrm{pH}=4.56(1: 99, \mathrm{v} / \mathrm{v})$ and filtered through a $0.45 \mu \mathrm{m}$ membrane and degassed by ultrasonication, prior to use. Solvent 
delivery was employed at a flow rate of $1 \mathrm{ml} . \mathrm{min}^{-1}$. Detection of the analytes were carried out at $254 \mathrm{~nm}$.

\section{2- (Benzoylamino)-3-methylbutyric acid (1)}

(2S)-2-Amino-3-methylbutyric acid (L-valine, $1.17 \mathrm{~g}, 0.01 \mathrm{~mol}$ ) was dissolved in sodium hydroxide solution $(100 \mathrm{ml}, 0.02 \mathrm{~mol})$ and benzoyl chloride $(1.40 \mathrm{~g}, 0.01 \mathrm{~mol})$ was added to the reaction medium with stirring in an ice bath. The crude product was precipitated by conc. $\mathrm{HCl}$, filtered and dried and washed with boiling petroleum ether. Yield 38\%. M.p. 136-137 ${ }^{\circ} \mathrm{C}(39)$. HPLC $t_{R}$ (min.): 1.5. IR, $v\left(\mathrm{~cm}^{-1}\right): 3298(\mathrm{~N}-\mathrm{H}), 3228$ (H-bonded O-H), 3066 (=C-H), 2960, 2874 (C-H), 1722, 1695 (C=O), 1639 $(\mathrm{C}=\mathrm{O})$.

\section{2- (Benzoylamino)-3-methylbutyric acid methyl ester (2)}

(2S)-2-(Benzoylamino)-3-methylbutyric acid (0.01 mol) was dissolved in $20 \mathrm{ml}$ methanol and $1 \mathrm{ml}$ conc. $\mathrm{H}_{2} \mathrm{SO}_{4}$ was added. The reaction mixture was heated under reflux for $3 \mathrm{~h}$. The crude product was precipitated by using $\mathrm{NaHCO}_{3}$ solution (5\%), filtered, dried and crystallized from petroleum ether. Yield $82 \%$. M.p. $111-114^{\circ} \mathrm{C}(40)$. HPLC $\mathrm{t}_{\mathrm{R}}$ (min.): 3.54 . IR, v ( $\mathrm{cm}^{-}$ 1): 3074 (=C-H), 2966, $2874(\mathrm{C}-\mathrm{H}), 1735(\mathrm{C}=\mathrm{O}), 1639(\mathrm{C}=\mathrm{O})$, 1240 (C-O).

\section{2- (Benzoylamino)-3-methylbutyric acid hydrazide (3)}

(2S)-2-(Benzoylamino)-3-methylbutyric acid methyl ester (0.01 $\mathrm{mol}$ ) and hydrazine hydrate were heated under reflux for $1 \mathrm{~h}$ and $25 \mathrm{ml}$ methanol was added to the reaction medium. The mixture was heated under reflux for $1 \mathrm{~h}$. The crude product was filtered and washed with boiling petroleum ether. Yield
77\%. M.p. $210-211^{\circ} \mathrm{C}(41)$. HPLC $t_{\mathrm{R}}$ (min.): 1.88. IR, v $\left(\mathrm{cm}^{-1}\right)$ : 3269, $3184(\mathrm{~N}-\mathrm{H}), 1660(\mathrm{C}=\mathrm{O}), 1624(\mathrm{C}=\mathrm{O})$.

General procedure for the synthesis of 1-[2-(benzoylamino)-3methylbutyryl]-4-alkyl/arylalkyl-thiosemicarbazides (4-8).

(2S)-2-(Benzoylamino)-3-methylbutyric acid hydrazide (0.01 mol) (3) was heated with methyl, ethyl, propyl, allyl, benzyl isothiocyanates $(0.01 \mathrm{~mol})$ under reflux for $4 \mathrm{~h}$ in ethanol. The crude products 4-8 were filtered and recrystallized from appropriate solvents.

General procedure for the synthesis of 2-[2-(benzoylamino)-3methylbutyrylhydrazono]-3-alkyl/arylalkyl-1,3-thiazolidinones (9-13).

A mixture of appropriate thiosemicarbazide 4-8 (0.01 mol), anhydrous sodium acetate $(99 \%, 0.04 \mathrm{~mol})$ and ethyl bromoacetate $(0.011 \mathrm{~mol})$ in $20 \mathrm{ml}$ absolute ethanol were heated under reflux for $4 \mathrm{~h}$. The mixture was cooled and the crude products (9-13) were filtered, dried and crystallized from appropriate solvents.

General procedure for the synthesis of 2-[2-(benzoylamino)-3methylbutyrylhydrazono]-3-alkyl/arylalkyl-5-methyl-1,3-thiazolidinones (14-18).

A mixture of appropriate thiosemicarbazide 4-8, anhydrous sodium acetate $(99 \%, 0.04 \mathrm{~mol})$ and ethyl 2-bromopropionate $(0.011 \mathrm{~mol})$ in $20 \mathrm{ml}$ absolute ethanol were heated under reflux for $20 \mathrm{~h}$. The mixture was evaporated under vacuo and extracted with chloroform to eliminate sodium acetate crystals. The organic phase was evaporated in vacuo and the oily product

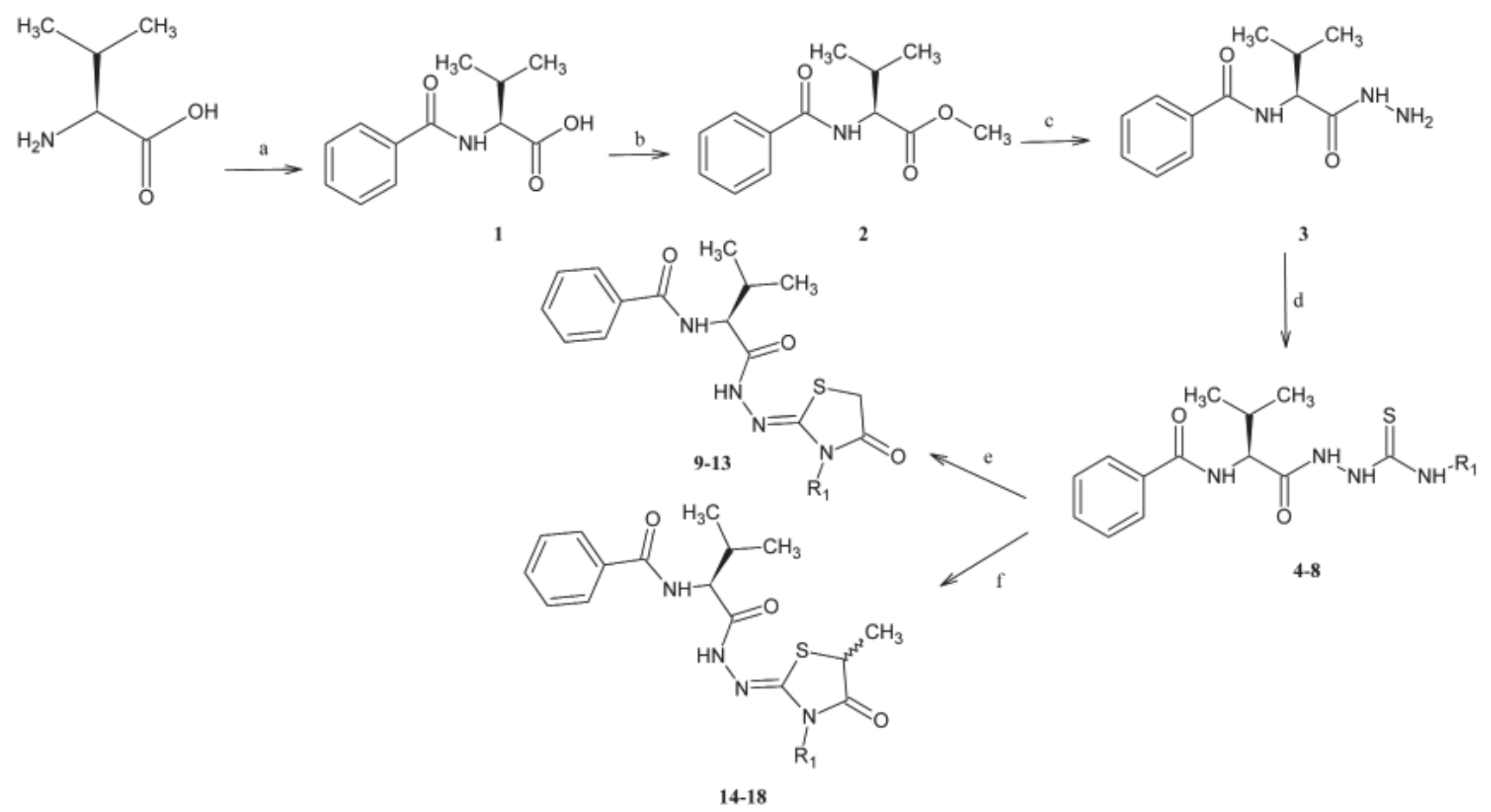

SCHEME 1. Synthetic route to compounds $\mathbf{1 - 1 8}$

Reagents and conditions: (a) $\mathrm{C}_{6} \mathrm{H}_{5} \mathrm{COCl} / \mathrm{NaOH}$; (b) $\mathrm{MeOH} / \mathrm{H}_{2} \mathrm{SO}_{4}$, reflux; (c) $\mathrm{NH}_{2} \mathrm{NH}_{2} \cdot \mathrm{H}_{2} \mathrm{O}$, reflux; (d) $\mathrm{R}_{1}-\mathrm{N}=\mathrm{C}=\mathrm{S}$, reflux; (e) $\mathrm{BrCH}_{2} \mathrm{COOC}_{2} \mathrm{H}_{5}$, anhydrous $\mathrm{CH}_{3} \mathrm{COONa}$, absolute $\mathrm{EtOH}$, reflux (f) $\mathrm{CH}_{3} \mathrm{CHBrCOOC}_{2} \mathrm{H}_{5}$, anhydrous $\mathrm{CH}_{3} \mathrm{COONa}$, absolute $\mathrm{EtOH}$, reflux. 
TABLE 1. Physical and spectral data for compounds 4-18.

\begin{tabular}{|c|c|c|c|c|c|c|}
\hline Compound & $\mathbf{R}_{1}$ & $\begin{array}{l}\text { Molecular } \\
\text { formula }\end{array}$ & M.p $\left({ }^{\circ} \mathrm{C}\right)$ & $\begin{array}{c}\text { Yield (\%) } \\
\& \\
\text { Crystallization solvent }\end{array}$ & $\begin{array}{c}\text { HPLC } \\
\text { Rt (min.) }\end{array}$ & $\begin{array}{l}\text { HREI/FAB-MS }(m / z) \\
\text { calculated/ found }\end{array}$ \\
\hline 4 & $\mathrm{CH}_{3}$ & $\mathrm{C}_{14} \mathrm{H}_{20} \mathrm{~N}_{4} \mathrm{O}_{2} \mathrm{~S}$ & $191-193$ & $\begin{array}{c}67 \\
\text { Ethanol }\end{array}$ & 5.835 & - \\
\hline 5 & $\mathrm{C}_{2} \mathrm{H}_{5}$ & $\mathrm{C}_{15} \mathrm{H}_{22} \mathrm{~N}_{4} \mathrm{O}_{2} \mathrm{~S}$ & $180-181$ & $\begin{array}{c}59 \\
\text { Ethanol }\end{array}$ & 7.542 & - \\
\hline 6 & $\mathrm{C}_{3} \mathrm{H}_{7}$ & $\mathrm{C}_{16} \mathrm{H}_{24} \mathrm{~N}_{4} \mathrm{O}_{2} \mathrm{~S}$ & $182-185$ & $\begin{array}{c}81 \\
\text { Ethanol }\end{array}$ & 10.850 & - \\
\hline 7 & $\mathrm{CH}_{2} \mathrm{CH}=\mathrm{CH}_{2}$ & $\mathrm{C}_{16} \mathrm{H}_{22} \mathrm{~N}_{4} \mathrm{O}_{2} \mathrm{~S}$ & $195-199$ & $\begin{array}{c}75 \\
\text { Ethanol }\end{array}$ & 8.431 & - \\
\hline 8 & $\mathrm{CH}_{2} \mathrm{C}_{6} \mathrm{H}_{5}$ & $\mathrm{C}_{20} \mathrm{H}_{24} \mathrm{~N}_{4} \mathrm{O}_{2} \mathrm{~S}$ & 205 & $\begin{array}{c}81 \\
\text { Ethanol }\end{array}$ & 26.606 & - \\
\hline 9 & $\mathrm{CH}_{3}$ & $\mathrm{C}_{16} \mathrm{H}_{20} \mathrm{~N}_{4} \mathrm{O}_{3} \mathrm{~S}$ & $218-220$ & $\begin{array}{c}53 \\
\text { Ethanol }\end{array}$ & 6.886 & 348.1256 / 348.1218 \\
\hline 10 & $\mathrm{C}_{2} \mathrm{H}_{5}$ & $\mathrm{C}_{17} \mathrm{H}_{22} \mathrm{~N}_{4} \mathrm{O}_{3} \mathrm{~S}$ & 227 & $\begin{array}{c}67 \\
\text { Ethanol }\end{array}$ & 8.647 & 362.1412 / 362.1438 \\
\hline 11 & $\mathrm{C}_{3} \mathrm{H}_{7}$ & $\mathrm{C}_{18} \mathrm{H}_{24} \mathrm{~N}_{4} \mathrm{O}_{3} \mathrm{~S}$ & 222-224 & $\begin{array}{c}90 \\
\text { Ethanol }\end{array}$ & 12.575 & 376.1569 / 376.1559 \\
\hline 12 & $\mathrm{CH}_{2} \mathrm{CH}=\mathrm{CH}_{2}$ & $\mathrm{C}_{18} \mathrm{H}_{22} \mathrm{~N}_{4} \mathrm{O}_{3} \mathrm{~S}$ & 205-207 & $\begin{array}{c}69 \\
\text { Ethanol }\end{array}$ & 10.483 & $374.1412 / 374.1418$ \\
\hline 13 & $\mathrm{CH}_{2} \mathrm{C}_{6} \mathrm{H}_{5}$ & $\mathrm{C}_{22} \mathrm{H}_{24} \mathrm{~N}_{4} \mathrm{O}_{3} \mathrm{~S}$ & $235-238$ & $\begin{array}{c}86 \\
\text { EtOH:DMF (99:1) }\end{array}$ & 39.037 & 424.1569 / 424.1567 \\
\hline 14 & $\mathrm{CH}_{3}$ & $\mathrm{C}_{17} \mathrm{H}_{22} \mathrm{~N}_{4} \mathrm{O}_{3} \mathrm{~S}$ & 183-185 & $\begin{array}{c}10 \\
\text { Diethylether }\end{array}$ & 9.821 & 362.1412 / 362.1422 \\
\hline 15 & $\mathrm{C}_{2} \mathrm{H}_{5}$ & $\mathrm{C}_{18} \mathrm{H}_{24} \mathrm{~N}_{4} \mathrm{O}_{3} \mathrm{~S}$ & 235 & $\begin{array}{c}62 \\
\mathrm{EtOH}: \mathrm{H}_{2} \mathrm{O}(50: 50)\end{array}$ & 12.809 & 376.1569 / 376.1571 \\
\hline 16 & $\mathrm{C}_{3} \mathrm{H}_{7}$ & $\mathrm{C}_{19} \mathrm{H}_{26} \mathrm{~N}_{4} \mathrm{O}_{3} \mathrm{Sc}^{\mathrm{c}}$ & $147 / 164$ & $\begin{array}{c}20 \\
\text { Diethylether }\end{array}$ & 16.758 & 391.1798 / 391.1809 \\
\hline 17 & $\mathrm{CH}_{2} \mathrm{CH}=\mathrm{CH}_{2}$ & $\mathrm{C}_{19} \mathrm{H}_{24} \mathrm{~N}_{4} \mathrm{O}_{3} \mathrm{~S}$ & $172-173$ & $\begin{array}{c}30 \\
\text { Ethanol }\end{array}$ & 14.804 & 388.1569 / 388.1558 \\
\hline 18 & $\mathrm{CH}_{2} \mathrm{C}_{6} \mathrm{H}_{5}$ & $\mathrm{C}_{23} \mathrm{H}_{26} \mathrm{~N}_{4} \mathrm{O}_{3} \mathrm{~S}$ & $192-194$ & $\begin{array}{c}54 \\
\text { Methanol }\end{array}$ & 56.690 & 438.1725 / 438.1706 \\
\hline \multicolumn{7}{|c|}{ 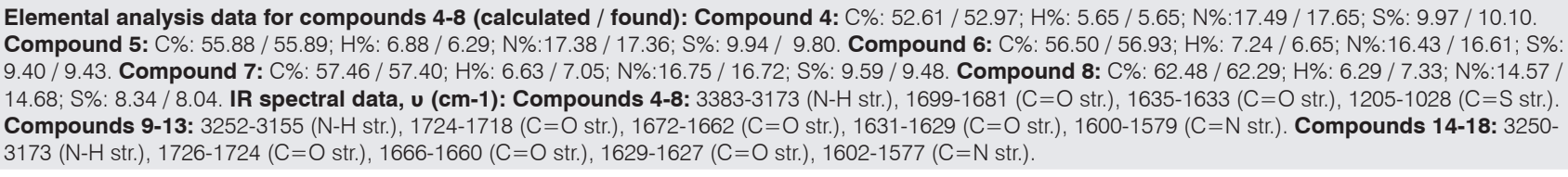 } \\
\hline
\end{tabular}

was triturated with ice-cold ether in order to be solidified. The crude products (14-18) were filtered, dried and recrystallized from appropriate solvents.

\section{In Vitro Antiviral Assays}

\section{Inhibition of HIV-induced cytopathicity in MT-4 cells}

Evaluation of the antiviral activity of the compounds against $H I V-1$ strain $I I_{B}$ and HIV-2 strain (ROD) in MT-4 cells was performed using the MTT assay as previously described (42). Stock solutions (10 $\mathrm{x}$ final concentration) of test compounds were added in $25 \mu \mathrm{l}$ volumes to two series of triplicate wells so as to allow simultaneous evaluation of their effects on mockand HIV-infected cells at the beginning of each experiment. Serial 5-fold dilutions of test compounds were made directly in flat-bottomed 96-well microtiter trays using a Biomek 2000 robot (Beckman instruments, Fullerton, CA). Untreated control HIV-and mock-infected cell samples were included for each samples.

HIV-1(III ${ }_{B}$ ) (43) or HIV-2 (ROD) (44) stock (50 $\left.\mu \mathrm{l}\right)$ at 100-300 $\mathrm{CCID}_{50}$ (cell culture infection dose) or culture medium was added to either the infected or mock-infected wells of the microtiter tray. Mock-infected cells were used to evaluate the ef- fect of test compound on uninfected cells in order to assess the cytotoxicity of the test compound. Exponentially growing MT-4 cells (45) were centrifuged for 5 minutes at $1000 \mathrm{rpm}$ and the supernatant was discarded. The MT-4 cells were resuspended at $6 \times 10^{5}$ cells $/ \mathrm{ml}$, and $50 \mu \mathrm{l}$ volumes were transferred to the microtiter tray wells. Five days after infection, the viability of mock-and HIV-infected cells was examined spectrophotometrically by the MTT assay.

The MTT assay is based on the reduction of yellow coloured 3-(4,5-dimethylthiazol-2-yl)-2,5-diphenyltetrazolium bromide (MTT) (Acros Organics, Geel, Belgium) by mitochondrial dehydrogenase of metabolically active cells to a blue-purple formazan that can be measured spectrophotometrically. The absorbances were read in an eight-channel computer-controlled photometer (Multiscan Ascent Reader, Labsystems, Helsinki, Finland), at two wavelenghths (540 and $690 \mathrm{~nm}$ ). All data were calculated using the median OD (optical density) value of tree wells. The $50 \%$ cytotoxic concentration $\left(C_{50}\right)$ was defined as the concentration of the test compound that reduced the absorbance $\left(\mathrm{OD}_{540}\right)$ of the mock-infected control sample by $50 \%$. The concentration achieving $50 \%$ protection 


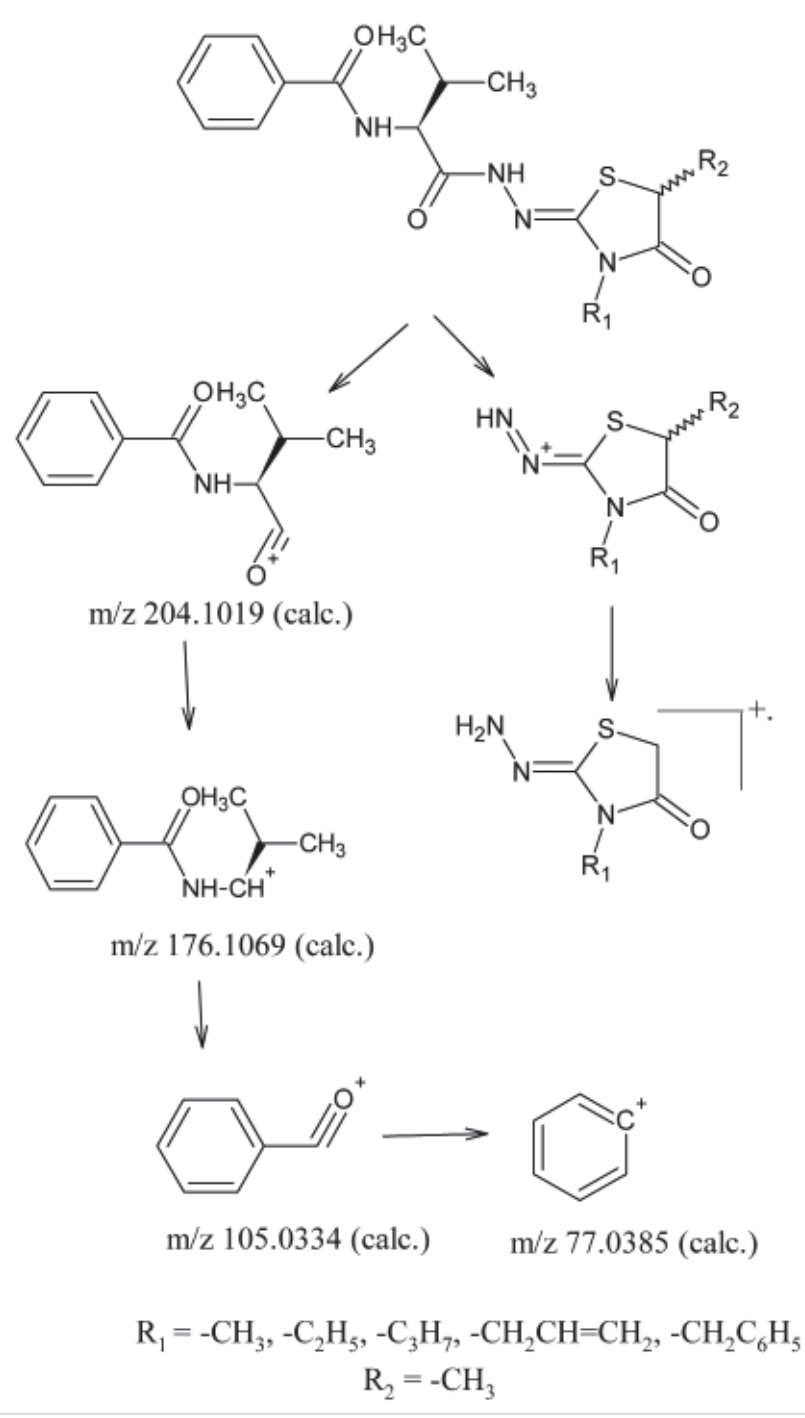

SCHEME 2. Common fragmentation pathway for the compounds $\mathbf{9 - 1 3}, \mathbf{1 4 - 1 5}, \mathbf{1 7 - 1 8}$

from the cytopathic effect of the virus in infected cells was defined as the $50 \%$ effective concentration $\left(\mathrm{EC}_{50}\right)$.

\section{Antiviral assays}

The antiviral assays, other than HIV-1, were based on inhibition of virus-induced cytopathicity in HEL cells (HSV-1(KOS), HSV-1(TK-KOS ACVr), HSV-2(G), Vaccinia virus, Vesicular stomatitis virus), hela cells (Vesicular stomatitis virus, Respiratory syncytial virus, Coxsackie B4 virus) and Vero cells (Parainfluenza-3 virus, Reovirus-1, Sindbis virus, Coxsackie B4 virus, Punta Toro virus), following previously established procedures (4648). Briefly, confluent cell cultures in microtiter 96-well plates were inoculated with $100 \mathrm{CCID}_{50}$ of virus, $1 \mathrm{CCID}_{50}$ being the virus dose required to infect $50 \%$ of the cell cultures. After a $1 \mathrm{~h}$ virus adsorption period, residual virus was removed, and the cell cultures were incubated in the presence of varying concentrations $400,200,100, \ldots \mu \mathrm{g} / \mathrm{ml}$ ) of the test compounds. Viral cytopathicity was recorded as soon as it reached completion in the control virus-infected cell cultures that had not been treated with the test compounds.

\section{NS5B inhibition assay}

The biological activity of the compounds against NS5B polymerase were evaluated in a reaction buffer containing $20 \mathrm{mM}$ Tris- $\mathrm{HCl}$ ( $\mathrm{pH} 7.0), 100 \mathrm{mM} \mathrm{NaCl}, 100 \mathrm{mM}$ sodium glutamate, $0.1 \mathrm{mM}$ DTT, $0.01 \%$ BSA, $0.01 \%$ Tween-20, 5\% glycerol, $20 \mathrm{U} /$ $\mathrm{mL}$ of RNase Out, $0.25 \mu \mathrm{M}$ of poly rA/ $\mathrm{U}_{12}, 25 \mu \mathrm{M} \mathrm{UTP}, 2 \mu \mathrm{Ci}$ [ $\infty 32$ P]UTP, $300 \mathrm{ng}$ of NS5BC $\Delta 21$ and $1.0 \mathrm{mM} \mathrm{MnCl}_{2}$ with or without inhibitors $(100 \mu \mathrm{M})$ in a total volume of $25 \mu \mathrm{l}$ for $1 \mathrm{~h}$ at $30^{\circ} \mathrm{C}$ as previously described $(20,49)$ Reactions were terminated by the addition of ice-cold $5 \%(\mathrm{v} / \mathrm{v})$ trichloroacetic acid (TCA) containing $0.5 \mathrm{mM}$ pyrophosphate. Reaction products were precipitated on GF-B filters and quantified on a liquid scintillation counter. NS5B activity in the presence of DMSO control was set at $100 \%$ and that in the presence of the compounds was determined relative to this control.

\section{RESULTS AND DISCUSSION Chemistry}

2-(Benzoylamino)-3-methylbutyric acid (1) was prepared by benzoylation of L-valine. 2-(Benzoylamino)-3-methylbutyric acid methyl ester (2) was obtained by esterification of compound 1. 2-(Benzoylamino)-3-methylbutyric acid hydrazide (3) was obtained by heating compound 2 with hydrazine hydrate. 1-[2-(Benzoylamino)-3-methylbutyryl]-4-alkyl/arylalkylthiosemicarbazides (4-8) were carried out by refluxing compound 3 with methyl, ethyl, propyl, allyl, benzyl isothiocyanates in ethanolic medium. 2-[2-(Benzoylamino)-3methylbutyrylhydrazono]-3-alkyl/arylalkyl-1,3-thiazolidine4-ones (9-13) were synthesized by refluxing compounds 4-8 with ethyl 2-bromoacetate in the presence of anhydrous sodium acetate in absolute ethanol. 2-[2-(Benzoylamino)-3methylbutyrylhydrazono]-3-alkyl/arylalkyl-5-methyl-1,3-thiazolidine-4-ones (14-18) were synthesized by refluxing compounds 4-8 with ethyl 2-bromopropionate in the presence of anhydrous sodium acetate in absolute ethanol.

Purities of compounds 4-18 were assessed through HPLC data and confirmed by elemental analysis. The synthesized compounds were characterized by their IR, ${ }^{1} \mathrm{H}-\mathrm{NMR},{ }^{13} \mathrm{C}-\mathrm{NMR}$, HR-EI and HR-FAB Mass Spectral data. Physical and spectral data for compounds 4-18 are given in Table 1.

The IR spectra of compound $\mathbf{1}$ was characterized by the presence of a new $\mathrm{C}=\mathrm{O}$ absorption band at $1639 \mathrm{~cm}^{-1}$. The bands at $1735 \mathrm{~cm}^{-1}$ and $1660 \mathrm{~cm}^{-1}$ were attributed to the $\mathrm{C}=\mathrm{O}$ streching band of ester (compound 2) and hydrazide (compound 3), respectively. Absorption bands at $1205-1028 \mathrm{~cm}^{-1}$, which were attributed to the $C=S$ streching vibrations, were observed in the IR spectra of compounds 4-8. New C=O bands (1718-1726 $\mathrm{cm}^{-1}$ ) in the IR spectra of 1,3-thiazolidine-4-ones 9-18 provided confirmatory evidence for ring closure $(3,7)$. IR spectral data for compounds 4-18 are given in Table 1.

The exhibited chemical shifts obtained from ${ }^{1} \mathrm{H}-\mathrm{NMR}$ spectra of compounds 4-8 (see Table 2) all supported the proposed structures of the compounds. Resonances assigned to the $\mathrm{N}^{1}$ $\mathrm{H}, \mathrm{N}^{2}-\mathrm{H}, \mathrm{N}^{4}-\mathrm{H}$ protons of thiosemicarbazides $4-8$ were detected at 10.17-10.31, 9.36-9.56, 7.61-8.25 ppm respectively which are supported by the literature (50).

Signals at about 4.02-4.12 ppm that were attributed to the $\mathrm{CH}_{2}$ protons at the $5^{\text {th }}$ position of the 1,3-thiazolidine-4-one ring, supported the exact structures of 9-13 (see Table 2). The $\mathrm{CH}$ 
TABLE 2. ${ }^{1} \mathrm{H}-\mathrm{NMR}$ and ${ }^{13} \mathrm{C}-\mathrm{NMR}$ spectral data for compounds 4-18

Comp.

${ }^{1} \mathrm{H}-\mathrm{NMR} \delta$ (ppm)

$4 \quad 0.79-1.16\left(\mathrm{~m}, 6 \mathrm{H},>\mathrm{CHCH}\left(\mathrm{CH}_{3}\right)_{2}\right), 2.07-2.26\left(\mathrm{q}, 1 \mathrm{H},>\mathrm{CHCH}\left(\mathrm{CH}_{3}\right)_{2}\right), 2.93\left(\mathrm{~d}, 3 \mathrm{H}, \mathrm{J}: 4.23 \mathrm{~Hz}, \mathrm{NH}-\mathrm{CH}_{3}\right), 4.02\left(\mathrm{brs}, 1 \mathrm{H},>\mathrm{CHCH}\left(\mathrm{CH}_{3}\right)_{2}\right), 7.47-7.59(\mathrm{~m}, 3 \mathrm{H}$, Ar- H), 7.78 (s, 1H, N4H), 7.89 (d, 2H, J:7.07 Hz, Ar- H), 8.65 (s, 1H, Ar-CONH-), 9.40 (s, 1H, N2-H), 10.17 (s, 1H, N1-H).

$5 \quad 0.95 \& 1.02\left(\mathrm{~d}, 3 \mathrm{H}, \mathrm{J}: 6.75 \mathrm{~Hz} \& \mathrm{~d}, 3 \mathrm{H}, \mathrm{J}: 6.59 \mathrm{~Hz},>\mathrm{CHCH}\left(\mathrm{CH}_{3}\right)_{2}\right), 1.12\left(\mathrm{t}, 3 \mathrm{H}, \mathrm{J}: 7.21 \mathrm{~Hz}, \mathrm{~J}: 7.21 \mathrm{~Hz}, \mathrm{NH}-\mathrm{CH}_{2}-\mathrm{CH}_{3}\right), 2.11-2.16\left(\mathrm{q}, 1 \mathrm{H},>\mathrm{CHCH}\left(\mathrm{CH}_{3}\right)_{2}\right), 3.42-$ $3.53\left(\mathrm{~m}, 2 \mathrm{H}, \mathrm{NH}-\mathrm{CH}_{2}-\mathrm{CH}_{3}\right), 3.93\left(\mathrm{brs}, 1 \mathrm{H},>\mathrm{CHCH}\left(\mathrm{CH}_{3}\right)_{2}\right), 7.49(\mathrm{t}, 2 \mathrm{H}, \mathrm{J}: 7.68 \mathrm{~Hz}, \mathrm{~J}: 7.09 \mathrm{~Hz}, \mathrm{Ar}-\mathrm{H}), 7.55-7.59(\mathrm{~m}, 1 \mathrm{H}, \mathrm{Ar}-\mathrm{H}), 7.64\left(\mathrm{~s}, 1 \mathrm{H}, \mathrm{N}^{4} \mathrm{H}-\mathrm{CH}_{2} \mathrm{CH}_{3}\right)$, $7.88(\mathrm{~d}, \mathrm{~J}: 7.68 \mathrm{~Hz}, 2 \mathrm{H}, \mathrm{Ar}-\mathrm{H}), 8.71(\mathrm{~s}, 1 \mathrm{H}, \mathrm{Ar}-\mathrm{CONH}-), 9.36\left(\mathrm{~s}, 1 \mathrm{H}, \mathrm{N}^{2}-\mathrm{H}\right), 10.21\left(\mathrm{~s}, 1 \mathrm{H}, \mathrm{N}^{1}-\mathrm{H}\right)$.

$6 \quad 0.82\left(\mathrm{t}, 3 \mathrm{H}, \mathrm{J}: 7.37 \mathrm{~Hz}, \mathrm{~J}: 7.44 \mathrm{~Hz}, \mathrm{NH}-\mathrm{CH}_{2}-\mathrm{CH}_{2}-\mathrm{CH}_{3}\right), 0.96$ \& $1.02\left(\mathrm{~d}, 3 \mathrm{H}, \mathrm{J}: 6.73 \mathrm{~Hz} \&\right.$ d, $\left.3 \mathrm{H}, \mathrm{J}: 6.58 \mathrm{~Hz},>\mathrm{CHCH}\left(\mathrm{CH}_{3}\right)_{2}\right), 1.51-1.57\left(\mathrm{~m}, 2 \mathrm{H}, \mathrm{NH}-\mathrm{CH}_{2}-\right.$ $\left.\mathrm{CH}_{2}-\mathrm{CH}_{3}\right), 2.11-2.17\left(\mathrm{q}, 1 \mathrm{H},>\mathrm{CHCH}\left(\mathrm{CH}_{3}\right)_{2}\right), 3.38-3.44\left(\mathrm{~m}, 2 \mathrm{H}, \mathrm{NH}-\mathrm{CH}_{2}-\mathrm{CH}_{2}-\mathrm{CH}_{3}\right), 3.93\left(\mathrm{brs}, 1 \mathrm{H},>\mathrm{CHCH}\left(\mathrm{CH}_{3}\right)_{2}\right), 7.49(\mathrm{t}, 2 \mathrm{H}, \mathrm{J}: 7.71 \mathrm{~Hz}, \mathrm{~J}: 7.11 \mathrm{~Hz}$, Ar-H), 7.55 (t, J:5.24 Hz, J: $4.31 \mathrm{~Hz}, 1 \mathrm{H}, \mathrm{Ar}-\mathrm{H}), 7.61(\mathrm{~s}, \mathrm{~N} 4 \mathrm{H}), 7.89$ (d, 2H, J: $7.11 \mathrm{~Hz}, \mathrm{Ar}-\mathrm{H}), 8.71$ (s, $1 \mathrm{H}, \mathrm{Ar}-\mathrm{CONH}-), 9.38\left(\mathrm{~s}, 1 \mathrm{H}, \mathrm{N}^{2}-\mathrm{H}\right), 10.22(\mathrm{~s}, 1 \mathrm{H}$, N1-H).

$70.96 \& 1.03\left(\mathrm{~d}, 3 \mathrm{H}, \mathrm{J}: 6.67 \mathrm{~Hz} \& \mathrm{t}, 3 \mathrm{H}, \mathrm{J}: 10.62 \mathrm{~Hz}, \mathrm{~J}: 6.55 \mathrm{~Hz},>\mathrm{CHCH}\left(\mathrm{CH}_{3}\right)_{2}\right), 2.14-2.17\left(\mathrm{q}, 1 \mathrm{H},>\mathrm{CHCH}\left(\mathrm{CH}_{3}\right)_{2}\right), 3.97\left(\mathrm{brs}, 1 \mathrm{H},>\mathrm{CHCH}\left(\mathrm{CH}_{3}\right)_{2}\right), 4.15$ (brs, $\left.2 \mathrm{H}, \mathrm{NH}-\mathrm{CH}_{2}-\mathrm{CH}_{2} \mathrm{CH}_{2}\right), 5.03\left(\mathrm{~d}, 1 \mathrm{H}, \mathrm{J}: 11.78 \mathrm{~Hz}, \mathrm{NH}-\mathrm{CH}_{2}-\mathrm{CH}_{2} \mathrm{CH}_{2}\right.$, cis), $5.13\left(\mathrm{~d}, 1 \mathrm{H}, \mathrm{J}: 18.91 \mathrm{~Hz}, \mathrm{NH}_{-}-\mathrm{CH}_{2}-\mathrm{CH}_{2} \mathrm{CH}_{2}\right.$, trans), $5.81-5.88(\mathrm{~m}, 1 \mathrm{H}$, NH- $\left.\mathrm{CH}_{2}-\mathrm{CH}_{=} \mathrm{CH}_{2}\right), 7.48(\mathrm{t}, 2 \mathrm{H}, \mathrm{J}: 7.82 \mathrm{~Hz}, \mathrm{~J}: 7.24 \mathrm{~Hz}, \mathrm{Ar}-\mathrm{H}), 7.54-7.58(\mathrm{t}, \mathrm{J}: 7.1 \mathrm{~Hz}, \mathrm{~J}: 6.29 \mathrm{~Hz}, 1 \mathrm{H}, \mathrm{Ar}-\mathrm{H}), 7.82(\mathrm{~s}, 1 \mathrm{H}, \mathrm{N} 4 \mathrm{H}), 7.86(\mathrm{~d}, 2 \mathrm{H}, \mathrm{J}: 7.88 \mathrm{~Hz}, \mathrm{Ar}-$ $\mathrm{H}), 8.70(\mathrm{~s}, 1 \mathrm{H}, \mathrm{Ar}-\mathrm{CONH}-), 9.49\left(\mathrm{~s}, 1 \mathrm{H}, \mathrm{N}^{2}-\mathrm{H}\right), 10.25\left(\mathrm{~s}, 1 \mathrm{H}, \mathrm{N}^{1}-\mathrm{H}\right)$.

$8 \quad 0.88-1.02\left(\mathrm{~m}, 6 \mathrm{H},>\mathrm{CHCH}\left(\mathrm{CH}_{3}\right)_{2}\right), 2.12-2.17\left(\mathrm{q}, 1 \mathrm{H},>\mathrm{CHCH}\left(\mathrm{CH}_{3}\right)_{2}\right), 3.96\left(\mathrm{brs}, 1 \mathrm{H},>\mathrm{CHCH}\left(\mathrm{CH}_{3}\right)_{2}\right), 4.73,4.77,4.83,4.87(4 \mathrm{~d}, 2 \mathrm{H}, \mathrm{J}: 5.28 \mathrm{~Hz}, \mathrm{~J}: 5.37$ $\left.\mathrm{Hz}, \mathrm{J}: 5.94 \mathrm{~Hz}, \mathrm{~J}: 6.10 \mathrm{~Hz}, \mathrm{NH}-\mathrm{CH}_{2}-\mathrm{C}_{6} \mathrm{H}_{5}\right), 7.17-7.31\left(\mathrm{~m}, 5 \mathrm{H}, \mathrm{NH}_{-}-\mathrm{CH}_{2}-\mathrm{C}_{6} \mathrm{H}_{5}\right), 7.38(\mathrm{t}, 2 \mathrm{H}, \mathrm{J}: 7.73 \mathrm{~Hz}, \mathrm{~J}: 7.58 \mathrm{~Hz}, \mathrm{Ar}-\mathrm{H}), 7.49-7.53(\mathrm{q}, 1 \mathrm{H}, \mathrm{Ar}-\mathrm{H}), 7.62(\mathrm{~d}, 2 \mathrm{H}$, J: $7.46 \mathrm{~Hz}, \mathrm{Ar}-\mathrm{H}), 8.25$ (s, N4H), 8.69 (d, 1H, J: $4.05 \mathrm{~Hz}$ Ar-CONH-), 9.56 (s, 1H, N2-H), 10.31 (s, 1H, N1-H).

$90.96\left(\mathrm{~d}, 6 \mathrm{H}, \mathrm{J}: 6.57 \mathrm{~Hz},>\mathrm{CHCH}\left(\mathrm{CH}_{3}\right)_{2}\right), 2.12-2.16\left(\mathrm{~m}, 1 \mathrm{H},>\mathrm{CHCH}\left(\mathrm{CH}_{3}\right)_{2}\right), 3.09\left(\mathrm{~d}, 2 \mathrm{H}, \mathrm{J}: 7.26 \mathrm{~Hz}, \mathrm{~N}-\mathrm{CH}_{3}\right), 4.03\left(\mathrm{~s}, 2 \mathrm{H},-\mathrm{SCH}_{2}-\right), 4.40(\mathrm{t}, 1 \mathrm{H}, \mathrm{J}: 8.62$ $\left.\mathrm{Hz}, \mathrm{J}: 8 ., 61 \mathrm{~Hz},>\mathrm{CHCH}\left(\mathrm{CH}_{3}\right)_{2}\right), 7.45-7.56(\mathrm{~m}, 3 \mathrm{H}, \mathrm{Ar}-\mathrm{H}), 7.88(\mathrm{~d}, 2 \mathrm{H}, \mathrm{J}: 8.52 \mathrm{~Hz}, \mathrm{Ar}-\mathrm{H}), 8.39(\mathrm{~d}, 1 \mathrm{H}, \mathrm{J}: 8.53 \mathrm{~Hz}, \mathrm{Ar}-\mathrm{CONH}-), 10.43(\mathrm{~s}, 1 \mathrm{H},-\mathrm{CO}-$ $\mathrm{NH}-\mathrm{N}=)$.

$10 \quad 0.94-0.99\left(\mathrm{q}, 6 \mathrm{H},>\mathrm{CHCH}\left(\mathrm{CH}_{3}\right)_{2}\right), 1.11-1.18\left(\mathrm{q}, 3 \mathrm{H}, \mathrm{N}-\mathrm{CH}_{2} \mathrm{CH}_{3}\right), 2.15-2.18\left(\mathrm{~m}, 1 \mathrm{H},>\mathrm{CHCH}\left(\mathrm{CH}_{3}\right)_{2}\right), 3.65-3.71\left(\mathrm{q}, 2 \mathrm{H}, \mathrm{N}-\mathrm{CH}_{2} \mathrm{CH}_{3}\right), 4.02 \& 4.05(\mathrm{~s} \& \mathrm{~s}$, $\left.2 \mathrm{H},-\mathrm{S}_{-} \mathrm{CH}_{2}-\right), 4.38\left(\mathrm{t}, 1 \mathrm{H}, \mathrm{J}: 8.53 \mathrm{~Hz}, \mathrm{~J}: 8.55 \mathrm{~Hz},>\mathrm{CHCH}\left(\mathrm{CH}_{3}\right)_{2}\right), 7.47(\mathrm{t}, 2 \mathrm{H}, \mathrm{J}: 7.58 \mathrm{~Hz}, \mathrm{~J}: 7.10 \mathrm{~Hz}, \mathrm{Ar}-\mathrm{H}), 7.54$ (t, $\left.1 \mathrm{H}, \mathrm{J}: 7.24 \mathrm{~Hz}, \mathrm{~J}: 7.17 \mathrm{~Hz}, \mathrm{Ar}-\mathrm{H}\right)$, $7.91(\mathrm{~d}, 2 \mathrm{H}, \mathrm{J}: 7.14 \mathrm{~Hz}, \mathrm{Ar}-\mathrm{H}), 8.39$ (d, $1 \mathrm{H}, \mathrm{J}: 8.43 \mathrm{~Hz}, \mathrm{Ar}-\mathrm{CONH}-)$, $10.43(\mathrm{~s}, 1 \mathrm{H},-\mathrm{CO}-\mathrm{NH}-\mathrm{N}=)$.

$110.85\left(\mathrm{t}, \mathrm{J}: 7.46 \mathrm{~Hz}, \mathrm{~J}: 7.42 \mathrm{~Hz}, 3 \mathrm{H}, \mathrm{N}-\mathrm{CH}_{2} \mathrm{CH}_{2} \mathrm{CH}_{3}\right), 0.94-0.99\left(\mathrm{~m}, 6 \mathrm{H},>\mathrm{CHCH}\left(\mathrm{CH}_{3}\right)_{2}\right), 1.57-1.63\left(\mathrm{q}, 2 \mathrm{H}, \mathrm{N}-\mathrm{CH}_{2} \mathrm{CH}_{2} \mathrm{CH}_{3}\right), 2.14-2.16(\mathrm{~m}, 1 \mathrm{H}$,

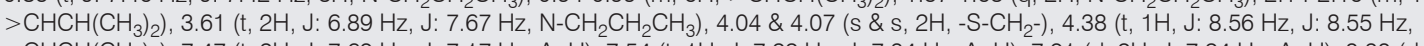
$\left.>\mathrm{CHCH}\left(\mathrm{CH}_{3}\right)_{2}\right), 7.47(\mathrm{t}, 2 \mathrm{H}, \mathrm{J}: 7.69 \mathrm{~Hz}, \mathrm{~J}: 7.17 \mathrm{~Hz}, \mathrm{Ar}-\mathrm{H}), 7.54(\mathrm{t}, 1 \mathrm{H}, \mathrm{J}: 7.22 \mathrm{~Hz}, \mathrm{~J}: 7.34 \mathrm{~Hz}, \mathrm{Ar}-\mathrm{H}), 7.91(\mathrm{~d}, 2 \mathrm{H}, \mathrm{J}: 7.24 \mathrm{~Hz}, \operatorname{Ar}-\mathrm{H}), 8.38$ (d, $1 \mathrm{H}, \mathrm{J}: 8.49$ $\mathrm{Hz}, \mathrm{Ar}-\mathrm{CONH}-), 10.42(\mathrm{~s}, 1 \mathrm{H},-\mathrm{CO}-\mathrm{NH}-\mathrm{N}=)$

$12 \quad 0.91-0.98\left(\mathrm{~m}, 6 \mathrm{H},>\mathrm{CHCH}\left(\mathrm{CH}_{3}\right)_{2}\right), 2.12-2.17\left(\mathrm{~m}, 1 \mathrm{H},>\mathrm{CHCH}\left(\mathrm{CH}_{3}\right)_{2}\right), 4.07\left(\mathrm{~s}, 2 \mathrm{H},-\mathrm{S}-\mathrm{CH}_{2}-\right), 4.25\left(\mathrm{~d}, 2 \mathrm{H}, \mathrm{NH}_{-} \mathrm{CH}_{2}-\mathrm{CH}_{=} \mathrm{CH}_{2}, \mathrm{~J}: 5.28 \mathrm{~Hz}\right), 4.38(\mathrm{t}, 1 \mathrm{H}, \mathrm{J}$ $\left.8.55 \mathrm{~Hz}, \mathrm{~J}: 8.55 \mathrm{~Hz},>\mathrm{CHCH}\left(\mathrm{CH}_{3}\right)_{2}\right), 5.13-5.18\left(\mathrm{~m}, 2 \mathrm{H}, \mathrm{NH}-\mathrm{CH}_{2}-\mathrm{CH}_{2} \mathrm{CH}_{2}\right), 5.79-5.86\left(\mathrm{~m}, 1 \mathrm{H}, \mathrm{NH}-\mathrm{CH}_{2}-\mathrm{CH}_{2} \mathrm{CH}_{2}\right), 7.45-7.56(\mathrm{~m}, 3 \mathrm{H}, \mathrm{Ar}-\mathrm{H}), 7.88(\mathrm{~d}, \mathrm{~J}$ : $8.54 \mathrm{~Hz}, 2 \mathrm{H}, \mathrm{Ar}-\mathrm{H}), 8.37$ (d, $1 \mathrm{H}, \mathrm{J}: 8.48 \mathrm{~Hz}, \mathrm{Ar}-\mathrm{CONH}-), 10.44$ (s, $1 \mathrm{H},-\mathrm{CO}-\mathrm{NH}-\mathrm{N}=)$.

$130.56,0.75,0.96-0.98\left(\mathrm{~d}, \mathrm{~J}: 6.79 \mathrm{~Hz}\right.$ d, J: $\left.6.75 \mathrm{~Hz}, \mathrm{q}, 6 \mathrm{H},>\mathrm{CHCH}\left(\mathrm{CH}_{3}\right)_{2}\right), 1.91-2.26\left(\mathrm{q}, 1 \mathrm{H},>\mathrm{CHCH}\left(\mathrm{CH}_{3}\right)_{2}\right), 4.12\left(\mathrm{~s}, 2 \mathrm{H},-\mathrm{S}-\mathrm{CH}_{2}-\right), 4.39(\mathrm{t}, 1 \mathrm{H}, \mathrm{J}: 8.53$ $\left.\mathrm{Hz}, \mathrm{J}: 8.55 \mathrm{~Hz},>\mathrm{CHCH}\left(\mathrm{CH}_{3}\right)_{2}\right), 4.84\left(\mathrm{~s}, 2 \mathrm{H}, \mathrm{N}-\mathrm{CH}_{2} \mathrm{C}_{6} \mathrm{H}_{5}\right), 7.27-7.29\left(\mathrm{~m}, 5 \mathrm{H}, \mathrm{N}-\mathrm{CH}_{2} \mathrm{C}_{6} \mathrm{H}_{5}\right), 7.44-7.54(\mathrm{~m}, 3 \mathrm{H}, \mathrm{Ar}-\mathrm{H}), 7.89(\mathrm{~d}, 2 \mathrm{H}, \mathrm{J}: 8.50 \mathrm{~Hz}, \mathrm{Ar}-\mathrm{H}), 8.38$ (d, $1 \mathrm{H}, \mathrm{J}: 8.55 \mathrm{~Hz}, \mathrm{Ar}-\mathrm{CONH}-), 10.48$ (s, 1H, -CO-NH-N=).

$140.96,1.09,1.24$ (d, J: $\left.6.68 \mathrm{~Hz}, \mathrm{t}, \mathrm{J}: 7.01 \mathrm{~Hz}, \mathrm{~J}: 7.03 \mathrm{~Hz}, \mathrm{~s}, 6 \mathrm{H},>\mathrm{CHCH}\left(\mathrm{CH}_{3}\right)_{2}\right), 1.51\left(\mathrm{~d}, 3 \mathrm{H}, \mathrm{J}: 7.18 \mathrm{~Hz},-\mathrm{S}-\mathrm{CH}_{-} \mathrm{CH}_{3}\right), 2.12-2.17\left(\mathrm{q}, 1 \mathrm{H},>\mathrm{CHCH}\left(\mathrm{CH}_{3}\right)_{2}\right)$, $3.10\left(\mathrm{~s}, 3 \mathrm{H}, \mathrm{J}: 7.23 \mathrm{~Hz}, \mathrm{~N}-\mathrm{CH}_{3}\right), 4.32-4.42\left(\mathrm{~m}, 2 \mathrm{H},-\mathrm{S}-\mathrm{CH}-\mathrm{CH}_{3} \&>\mathrm{CHCH}\left(\mathrm{CH}_{3}\right)_{2}\right), 7.45-7.56(\mathrm{~m}, 3 \mathrm{H}, \mathrm{Ar}-\mathrm{H}), 7.88(\mathrm{~d}, 2 \mathrm{H}, \mathrm{J}: 7.24 \mathrm{~Hz}, \mathrm{Ar}-\mathrm{H}), 8.38(\mathrm{~d}, 1 \mathrm{H}, \mathrm{J}$ : $8.46 \mathrm{~Hz}, \mathrm{Ar}-\mathrm{CONH}-), 10.42(\mathrm{~s}, 1 \mathrm{H},-\mathrm{CO}-\mathrm{NH}-\mathrm{N}=)$.

$15 \quad 0.82-1.24\left(\mathrm{~m}, 9 \mathrm{H}>\mathrm{CHCH}\left(\mathrm{CH}_{3}\right)_{2}, \mathrm{~N}-\mathrm{CH}_{2} \mathrm{CH}_{3}\right), 1.50 \& 1.60\left(\mathrm{~d}, \mathrm{~J}: 7.18 \mathrm{~Hz} \& \mathrm{~d}, \mathrm{~J}: 7.26 \mathrm{~Hz} 3 \mathrm{H},-\mathrm{S}-\mathrm{CH}-\mathrm{CH}_{3}\right), 2.06-2.17\left(\mathrm{~m}, 1 \mathrm{H},>\mathrm{CHCH}\left(\mathrm{CH}_{3}\right)_{2}\right), 3.62(\mathrm{t}$, $\left.2 \mathrm{H}, \mathrm{J}: 6.55 \mathrm{~Hz}, \mathrm{~J}: 7.93 \mathrm{~Hz} \mathrm{~N}-\mathrm{CH}_{2} \mathrm{CH}_{3}\right), 4.01-4.39\left(\mathrm{~m}, 2 \mathrm{H},>\mathrm{CHCH}\left(\mathrm{CH}_{3}\right)_{2} \&-\mathrm{S}-\mathrm{CH}-\mathrm{CH}_{3}\right), 7.44-7.55(\mathrm{~m}, 3 \mathrm{H}, \mathrm{Ar}-\mathrm{H}), 7.78-7.91(\mathrm{~m}, 2 \mathrm{H}, \mathrm{Ar}-\mathrm{H}), 8.29-8.41(\mathrm{~m}$, $1 \mathrm{H}, \mathrm{Ar}-\mathrm{CONH}-), 9.45 \& 10.43$ (s \& s, $1 \mathrm{H},-\mathrm{CO}-\mathrm{NH}-\mathrm{N}=$ ).

$16 \quad 0.85-1.22\left(\mathrm{~m}, 9 \mathrm{H}>\mathrm{CHCH}\left(\mathrm{CH}_{3}\right)_{2}, \mathrm{~N}-\mathrm{CH}_{2} \mathrm{CH}_{2} \mathrm{CH}_{3}\right), 1.49\left(\mathrm{~d}, 3 \mathrm{H}, \mathrm{J}: 7.18 \mathrm{~Hz},-\mathrm{S}-\mathrm{CH}-\mathrm{CH}_{3}\right), 1.63\left(\mathrm{~s}, 2 \mathrm{H}, \mathrm{N}-\mathrm{CH}_{2} \mathrm{CH}_{2} \mathrm{CH}_{3}\right), 2.12-2.20(\mathrm{~m}, 1 \mathrm{H}$, $\left.>\mathrm{CHCH}\left(\mathrm{CH}_{3}\right)_{2}\right), 3.65-3.71\left(\mathrm{q}, 2 \mathrm{H}, \mathrm{N}-\mathrm{CH}_{2} \mathrm{CH}_{2} \mathrm{CH}_{3}\right), 3.88-4.47\left(\mathrm{~m}, 2 \mathrm{H},>\mathrm{CHCH}\left(\mathrm{CH}_{3}\right)_{2}\right.$ \& $\left.-\mathrm{S}-\mathrm{CH}-\mathrm{CH}_{3}\right), 7.43-7.55(\mathrm{~m}, 3 \mathrm{H}, \mathrm{Ar}-\mathrm{H}), 7.85-7.92(\mathrm{~m}, 2 \mathrm{H}, \mathrm{Ar}-\mathrm{H})$, $8.52 \& 8.66(\mathrm{~d}, \mathrm{~J}: 8.79 \mathrm{~Hz} \& \mathrm{~s}, 1 \mathrm{H}, \mathrm{Ar}-\mathrm{CONH}-), 9.45(\mathrm{~s}, 1 \mathrm{H},-\mathrm{CO}-\mathrm{NH}-\mathrm{N}=)$.

$170.93,0.96 \& 1.24$ (d, J: $\left.6.23 \mathrm{~Hz}, \mathrm{~d}, \mathrm{~J}: 6.71 \mathrm{~Hz} \& \mathrm{~s}, 6 \mathrm{H},>\mathrm{CHCH}\left(\mathrm{CH}_{3}\right)_{2}\right), 1.53\left(\mathrm{~d}, 3 \mathrm{H}, \mathrm{J}: 7.25 \mathrm{~Hz},-\mathrm{S}-\mathrm{CH}-\mathrm{CH}_{3}\right), 2.13\left(\mathrm{~m}, 1 \mathrm{H},>\mathrm{CHCH}\left(\mathrm{CH}_{3}\right)_{2}\right), 4.25(\mathrm{~d}$, $\left.2 \mathrm{H}, \mathrm{NH}-\mathrm{CH}_{2}-\mathrm{CH}_{2} \mathrm{CH}_{2}, \mathrm{~J}: 5.28 \mathrm{~Hz}\right), 4.36-4.41\left(\mathrm{~m}, 2 \mathrm{H},-\mathrm{S}-\mathrm{CH}_{-} \mathrm{CH}_{3} \&>\mathrm{CHCH}\left(\mathrm{CH}_{3}\right)_{2}\right), 5.11-5.16\left(\mathrm{~m}, 2 \mathrm{H}, \mathrm{NH}_{-} \mathrm{CH}_{2}-\mathrm{CH}_{=} \mathrm{CH}_{2}\right), 5.80-5.87\left(\mathrm{q}, 1 \mathrm{H}, \mathrm{NH}-\mathrm{CH}_{2}-\right.$ $\left.\mathrm{CH}_{=} \mathrm{CH}_{2}\right), 7.45-7.54(\mathrm{~m}, 3 \mathrm{H}, \mathrm{Ar}-\mathrm{H}), 7.88(\mathrm{t}, 2 \mathrm{H}, \mathrm{J}: 7.05 \mathrm{~Hz}, \mathrm{~J}: 6.65 \mathrm{~Hz}, \mathrm{Ar}-\mathrm{H}), 8.36$ \& 8.38 (dd, J: 2.56Hz, J: $\left.2.55 \mathrm{~Hz}, 1 \mathrm{H}, \mathrm{Ar}-\mathrm{CONH}-\right), 10.43(\mathrm{~s}, 1 \mathrm{H},-\mathrm{CO}-$ $\mathrm{NH}-\mathrm{N}=)$.

$180.65-0.67,0.83,0.97\left(\mathrm{q}, \mathrm{d}, \mathrm{J}: 6.73 \mathrm{~Hz}, \mathrm{~d}, \mathrm{~J}: 6.71 \mathrm{~Hz}, 6 \mathrm{H},>\mathrm{CHCH}\left(\mathrm{CH}_{3}\right)_{2}\right), 1.52-1.59\left(\mathrm{~m}, 3 \mathrm{H},-\mathrm{S}-\mathrm{CH}_{-}-\mathrm{CH}_{3}\right), 2.11-2.17\left(\mathrm{q}, 1 \mathrm{H},>\mathrm{CHCH}\left(\mathrm{CH}_{3}\right)_{2}\right), 4.37-4.47$ $\left(\mathrm{m}, 2 \mathrm{H},-\mathrm{S}-\mathrm{CH}-\mathrm{CH}_{3} \&>\mathrm{CHCH}\left(\mathrm{CH}_{3}\right)_{2}\right), 4.80-4.86\left(\mathrm{~m}, 2 \mathrm{H}, \mathrm{N}^{-} \mathrm{CH}_{2} \mathrm{C}_{6} \mathrm{H}_{5}\right), 7.25-7.56\left(\mathrm{~m}, 8 \mathrm{H}, \mathrm{N}-\mathrm{CH}_{2} \mathrm{C}_{6} \mathrm{H}_{5}, \mathrm{Ar}-\mathrm{H}\right), 7.87-7.90(\mathrm{q}, 2 \mathrm{H}, \mathrm{Ar}-\mathrm{H}), 8.35-8.38(\mathrm{dd}, \mathrm{J}$ : $3.18 \mathrm{~Hz}, \mathrm{~J}: 3.12 \mathrm{~Hz}, 1 \mathrm{H}, \mathrm{Ar}-\mathrm{CONH}-), 10.47(\mathrm{~s}, 1 \mathrm{H},-\mathrm{CO}-\mathrm{NH}-\mathrm{N}=)$.

${ }^{13}$ C-NMR (DEPT) spectral data: Compound 13: 19.56 \& 19.83 (>CHCH(CH3)2), 30.51 (>CHCH(CH3)2), 33.17 (thiazolidinone-C5), 45.95 (>N-CH2-C6H5), 58.47 (>CHCH(CH3)2), 127.97 (Ar-C3, Ar-C5, Ar-C2', Ar-C6'), 128.05 \& 128.33 (Ar-C2, Ar-C6), 128.64 \& 128.83 (Ar-C4'), 128.95 (Ar-C3', Ar-C5'), 131.74 (Ar-C4), 134.64 (Ar-C1), 136.35 (Ar-C1'), 159.45 (thiazolidinone-C2),

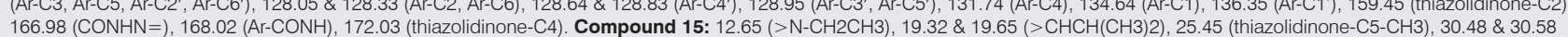

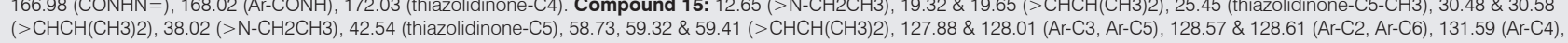
$134.75 \& 134.87$ (Ar-C1), 166.75 (thiazolidinone-C2), 168.22 (CONHN=), 170.91 (Ar-CONH), 173.63, 174.65 \& 174,72 (thiazolidinone-C4).

proton at the $5^{\text {th }}$ position of the 1,3-thiazolidine-4-on ring and the hydrogen attached to the chiral carbon were detected as a multiplet signal between 3.88-4.47 ppm in the ${ }^{1} \mathrm{H}-\mathrm{NMR}$ spectra of the compounds 14-18 (See Table 2). The methyl protons at the $5^{\text {th }}$ position of the 1,3-thiazolidine-4-on ring were detected between 1.49-1.59 ppm in accordance with literature (51). The endocyclic $-\mathrm{CH}_{2}$ - protons are expected to be detected as a singlet peak with an integration of two protons but in our work they were detected as two singlet peaks with an integration of two protons in the ${ }^{1} \mathrm{H}-\mathrm{NMR}$ spectra of compounds 10-11 and this revealed the presence of two isomers. The methyl proton attached to the endocyclic- $\mathrm{CH}$-proton is used to be detected as a doublet but in our work we observed these protons as two doublets with an integration of one proton in the ${ }^{1} \mathrm{H}-\mathrm{NMR}$ spectra of compound 15. Compounds $\mathbf{1 3}$ and $\mathbf{1 5}$ were selected as prototypes and ${ }^{13} \mathrm{C}$-NMR spectra of these compounds were observed for further support of geometric isomerism (see Table 2). Detecting $\mathrm{C}=\mathrm{O}$ of the thiazolidinone ring (only for compound 15) and some of the aliphatic and aromatic $\mathrm{C}$ atoms 
TABLE 3. Anti-Feline Corona Virus (FIPV) and anti-Feline Herpes Virus activity and cytotoxicity of compounds 4-18 in CRFK cell cultures.

\begin{tabular}{|c|c|c|c|}
\hline \multirow[b]{2}{*}{ Compound } & \multirow[b]{2}{*}{$\mathrm{CC}_{50} \mathrm{a}^{\mathrm{a}}(\mu \mathrm{M})$} & \multicolumn{2}{|c|}{$\mathrm{EC}_{50} \mathrm{~b}(\mu \mathrm{M})$} \\
\hline & & $\begin{array}{l}\text { Feline Corona } \\
\text { Virus(FIPV) }\end{array}$ & $\begin{array}{c}\text { Feline } \\
\text { Herpes Virus }\end{array}$ \\
\hline 4 & $>100$ & $>100$ & $>100$ \\
\hline 5 & $>100$ & $>100$ & $>100$ \\
\hline 6 & $>100$ & $>100$ & $>100$ \\
\hline 7 & $>100$ & $>100$ & $>100$ \\
\hline 8 & 85.3 & $>20$ & $>20$ \\
\hline 9 & $>100$ & $>100$ & $>100$ \\
\hline 10 & $>100$ & $>100$ & $>100$ \\
\hline 11 & $>100$ & $>100$ & $>100$ \\
\hline 12 & $>100$ & $>100$ & $>100$ \\
\hline 13 & $>100$ & $>100$ & $>100$ \\
\hline 14 & $>100$ & $>100$ & $>100$ \\
\hline 15 & $>100$ & $>100$ & $>100$ \\
\hline 16 & $>100$ & $>100$ & $>100$ \\
\hline 17 & $>100$ & $>100$ & $>100$ \\
\hline 18 & $>100$ & $>100$ & $>100$ \\
\hline HHA ( $\mu \mathrm{g} / \mathrm{ml})$ & $>100$ & 0.8 & 2.7 \\
\hline UDA ( $\mu \mathrm{g} / \mathrm{ml})$ & $>100$ & 1.6 & 2.6 \\
\hline Ganciclovir & $>100$ & $>100$ & 2.9 \\
\hline
\end{tabular}

TABLE 4. Cytotoxicity and antiviral activity of compounds 4-18 in HEL cell cultures.

\begin{tabular}{|c|c|c|c|c|c|c|}
\hline \multirow[b]{2}{*}{ Compound } & \multirow[b]{2}{*}{$\begin{array}{l}\text { Minimum cytotoxic } \\
\text { concentration }{ }^{\mathrm{a}}(\mu \mathrm{M})\end{array}$} & \multicolumn{5}{|c|}{$\mathrm{EC}_{50} \mathrm{~b}(\mu \mathrm{M})$} \\
\hline & & $\begin{array}{l}\text { Herpes simplex } \\
\text { virus-1 (KOS) }\end{array}$ & $\begin{array}{l}\text { Herpes simplex } \\
\quad \text { virus-2 (G) }\end{array}$ & $\begin{array}{l}\text { Vaccinia } \\
\text { virus }\end{array}$ & $\begin{array}{c}\text { Vesicular } \\
\text { stomatitis virus }\end{array}$ & $\begin{array}{c}\text { Herpes simplex virus-1 } \\
\text { TK- KOS ACV }\end{array}$ \\
\hline 4 & $>100$ & $>100$ & $>100$ & $>100$ & $>100$ & $>100$ \\
\hline 5 & $>100$ & $>100$ & $>100$ & $>100$ & $>100$ & $>100$ \\
\hline 6 & $>100$ & $>100$ & $>100$ & $>100$ & $>100$ & $>100$ \\
\hline 7 & $>100$ & $>100$ & $>100$ & $>100$ & $>100$ & $>100$ \\
\hline 8 & $>100$ & $>100$ & $>100$ & $>100$ & $>100$ & $>100$ \\
\hline 9 & $>100$ & $>100$ & $>100$ & $>100$ & $>100$ & $>100$ \\
\hline 10 & $>100$ & $>100$ & $>100$ & $>100$ & $>100$ & $>100$ \\
\hline 11 & $>100$ & $>100$ & $>100$ & $>100$ & $>100$ & $>100$ \\
\hline 12 & $>100$ & $>100$ & $>100$ & $>100$ & $>100$ & $>100$ \\
\hline 13 & $>100$ & $>100$ & $>100$ & $>100$ & $>100$ & $>100$ \\
\hline 14 & $>100$ & $>100$ & $>100$ & $>100$ & $>100$ & $>100$ \\
\hline 15 & $>100$ & $>100$ & $>100$ & $>100$ & $>100$ & $>100$ \\
\hline 16 & $>100$ & $>100$ & $>100$ & $>100$ & $>100$ & $>100$ \\
\hline 17 & $>100$ & $>100$ & $>100$ & $>100$ & $>100$ & $>100$ \\
\hline 18 & $>100$ & $>100$ & $>100$ & $>100$ & $>100$ & $>100$ \\
\hline Brivudin & $>250$ & 0.04 & 10 & 2 & $>250$ & 50 \\
\hline Ribavirin & $>250$ & 50 & 50 & 5 & $>250$ & 150 \\
\hline Acyclovir & $>250$ & 0.4 & 0.4 & 146 & $>250$ & 50 \\
\hline Ganciclovir & $>100$ & 0.03 & 0.03 & $>250$ & $>100$ & 0.8 \\
\hline
\end{tabular}

aRequired to cause a microscopically detectable alteration of normal cell morphology. ${ }^{\text {}}$ Required to reduce virus-induced cytopathogenicity by $50 \%$.

(compound 13 and 15) as two peaks instead of one, provided confirmatory evidence for geometric isomerism (52-54).

In the HR mass spectra, compounds 9-13 fragmented via a prominent pathway to afford fragment at m/z 204.1019 by
-CONH bond cleavage and 2-hydrazinylidene-3-methyl-1,3thiazolidin-4-one moiety. By expulsion of $\mathrm{CO}$ from $\mathrm{m} / \mathrm{z}$ 204.1019 fragment, 2-methyl-1-[(phenylcarbonyl)amino]prop1-ylium cation (m/z 176.1069) was detected. Benzoyl cation 
TABLE 5. Cytotoxicity and antiviral activity of compounds 4-18 in HeLa cell cultures.

\begin{tabular}{|c|c|c|c|c|}
\hline \multirow[b]{2}{*}{ Compound } & \multirow[b]{2}{*}{$\begin{array}{l}\text { Minimum cytotoxic } \\
\text { concentration }(\mu \mathrm{M})\end{array}$} & \multicolumn{3}{|c|}{$\mathrm{EC}_{50^{\mathrm{b}}}(\mu \mathrm{M})$} \\
\hline & & $\begin{array}{c}\text { Vesicular } \\
\text { stomatitis } \\
\text { virus }\end{array}$ & $\begin{array}{l}\text { Coxsackie } \\
\text { virus B4 }\end{array}$ & $\begin{array}{l}\text { Respiratory } \\
\text { syncytial } \\
\text { virus }\end{array}$ \\
\hline 4 & $>100$ & $>100$ & $>100$ & $>100$ \\
\hline 5 & $>100$ & $>100$ & $>100$ & $>100$ \\
\hline 6 & $>100$ & $>100$ & $>100$ & $>100$ \\
\hline 7 & $>100$ & $>100$ & $>100$ & $>100$ \\
\hline 8 & $>100$ & $>100$ & $>100$ & $>100$ \\
\hline 9 & $>100$ & $>100$ & $>100$ & $>100$ \\
\hline 10 & $>100$ & $>100$ & $>100$ & $>100$ \\
\hline 11 & $>100$ & $>100$ & $>100$ & $>100$ \\
\hline 12 & $>100$ & $>100$ & $>100$ & $>100$ \\
\hline 13 & $>100$ & $>100$ & $>100$ & $>100$ \\
\hline 14 & $>100$ & $>100$ & $>100$ & $>100$ \\
\hline 15 & $>100$ & $>100$ & $>100$ & $>100$ \\
\hline 16 & $>100$ & $>100$ & $>100$ & $>100$ \\
\hline 17 & $>100$ & $>100$ & $>100$ & $>100$ \\
\hline 18 & $>100$ & $>100$ & $>100$ & $>100$ \\
\hline Brivudin & $>250$ & $>250$ & $>250$ & $>250$ \\
\hline (S)-DHPA & $>250$ & 146 & $>250$ & $>250$ \\
\hline Ribavirin & $>250$ & 2 & 146 & 10 \\
\hline
\end{tabular}

TABLE 6. Cytotoxicity and antiviral activity of compounds 4-18 in Vero cell cultures.

\begin{tabular}{|c|c|c|c|c|c|c|}
\hline \multirow[b]{2}{*}{ Compound } & \multirow[b]{2}{*}{$\begin{array}{l}\text { Minimum cytotoxic } \\
\text { concentrationa }(\mu \mathrm{M})\end{array}$} & \multicolumn{5}{|c|}{$\mathrm{EC}_{50^{\mathrm{b}}}(\mu \mathrm{M})$} \\
\hline & & $\begin{array}{l}\text { Para-influenza-3 } \\
\text { virus }\end{array}$ & Reovirus-1 & $\begin{array}{l}\text { Sindbis } \\
\text { virus }\end{array}$ & $\begin{array}{c}\text { Coxsackie } \\
\text { virus } \\
\text { B4 }\end{array}$ & $\begin{array}{l}\text { Punta } \\
\text { Toro } \\
\text { virus }\end{array}$ \\
\hline 4 & $>100$ & $>100$ & $>100$ & $>100$ & $>100$ & $>100$ \\
\hline 5 & $>100$ & $>100$ & $>100$ & $>100$ & $>100$ & $>100$ \\
\hline 6 & $>100$ & $>100$ & $>100$ & $>100$ & $>100$ & $>100$ \\
\hline 7 & $>100$ & $>100$ & $>100$ & $>100$ & $>100$ & $>100$ \\
\hline 8 & $>100$ & $>100$ & $>100$ & $>100$ & $>100$ & $>100$ \\
\hline 9 & $>100$ & $>100$ & $>100$ & $>100$ & $>100$ & $>100$ \\
\hline 10 & $>100$ & $>100$ & $>100$ & $>100$ & $>100$ & $>100$ \\
\hline 11 & $>100$ & $>100$ & $>100$ & $>100$ & $>100$ & $>100$ \\
\hline 12 & $>100$ & $>100$ & $>100$ & $>100$ & $>100$ & $>100$ \\
\hline 13 & $>100$ & $>100$ & $>100$ & $>100$ & $>100$ & $>100$ \\
\hline 14 & $>100$ & $>100$ & $>100$ & $>100$ & $>100$ & $>100$ \\
\hline 15 & $>100$ & $>100$ & $>100$ & $>100$ & $>100$ & $>100$ \\
\hline 16 & $>100$ & $>100$ & $>100$ & $>100$ & $>100$ & $>100$ \\
\hline 17 & $>100$ & $>100$ & $>100$ & $>100$ & $>100$ & $>100$ \\
\hline 18 & $>100$ & $>100$ & $>100$ & $>100$ & $>100$ & $>100$ \\
\hline Brivudin & $>250$ & $>250$ & $>250$ & $>250$ & $>250$ & $>250$ \\
\hline$(\underline{S})-D H P A$ & $>250$ & 50 & $>250$ & $>250$ & $>250$ & $>250$ \\
\hline Ribavirin & $>250$ & 50 & $>250$ & $>250$ & $>250$ & 150 \\
\hline
\end{tabular}


Tatar et al., Marmara Pharm J 16: 181-193, 2012.

TABLE 7. Anti-HIV activity and cytotoxicity of compounds 4-18.

\begin{tabular}{|c|c|c|c|c|c|}
\hline Compound & Strain & $\mathrm{IC}_{50}(\mu \mathrm{g} / \mathrm{ml})$ & $\mathrm{CC}_{50}(\mu \mathrm{g} / \mathrm{ml})$ & SI & $\begin{array}{r}\text { Maximum } P \\
\text { rotection (\%) }\end{array}$ \\
\hline \multirow[t]{2}{*}{4} & \|\|$_{B}$ & $\begin{array}{l}>125 \\
>125\end{array}$ & $\begin{array}{l}>125 \\
>125\end{array}$ & $\begin{array}{l}X 1 \\
\times 1\end{array}$ & $\begin{array}{l}6 \\
0\end{array}$ \\
\hline & ROD & $\begin{array}{l}>125 \\
>125\end{array}$ & $\begin{array}{l}>125 \\
>125\end{array}$ & $\begin{array}{l}X 1 \\
\times 1\end{array}$ & $\begin{array}{l}6 \\
2\end{array}$ \\
\hline \multirow[t]{2}{*}{5} & \|\|$_{B}$ & $\begin{array}{l}>125 \\
>125\end{array}$ & $\begin{array}{l}>125 \\
>125\end{array}$ & $\begin{array}{l}\times 1 \\
\times 1\end{array}$ & $\begin{array}{l}4 \\
1\end{array}$ \\
\hline & ROD & $\begin{array}{l}>125 \\
>125\end{array}$ & $\begin{array}{l}>125 \\
>125\end{array}$ & $\begin{array}{l}\times 1 \\
\times 1\end{array}$ & $\begin{array}{l}6 \\
4\end{array}$ \\
\hline \multirow[t]{2}{*}{6} & \|\|$_{B}$ & $\begin{array}{l}>125 \\
>119\end{array}$ & $\begin{array}{l}>125 \\
=119\end{array}$ & $\begin{array}{l}X 1 \\
<1\end{array}$ & $\begin{array}{l}4 \\
1\end{array}$ \\
\hline & ROD & $\begin{array}{l}>125 \\
>125\end{array}$ & $\begin{array}{l}>125 \\
>125\end{array}$ & $\begin{array}{l}X 1 \\
\times 1\end{array}$ & $\begin{array}{l}4 \\
0\end{array}$ \\
\hline \multirow[t]{2}{*}{7} & \|\|$_{B}$ & $\begin{array}{l}>125 \\
>125\end{array}$ & $\begin{array}{l}>125 \\
>125\end{array}$ & $\begin{array}{l}\times 1 \\
\times 1\end{array}$ & $\begin{array}{l}3 \\
1\end{array}$ \\
\hline & ROD & $\begin{array}{l}>125 \\
>125\end{array}$ & $\begin{array}{l}>125 \\
>125\end{array}$ & $\begin{array}{l}X 1 \\
\times 1\end{array}$ & $\begin{array}{l}5 \\
4\end{array}$ \\
\hline \multirow[t]{2}{*}{8} & \|\|$_{B}$ & $\begin{array}{l}>66.1 \\
>72.7\end{array}$ & $\begin{array}{l}=66.1 \\
=72.7\end{array}$ & $\begin{array}{l}<1 \\
<1\end{array}$ & $\begin{array}{l}4 \\
1\end{array}$ \\
\hline & $\mathrm{ROD}$ & $\begin{array}{l}>73.5 \\
>68.1\end{array}$ & $\begin{array}{l}=73.5 \\
=68.1\end{array}$ & $\begin{array}{l}<1 \\
<1\end{array}$ & $\begin{array}{l}2 \\
0\end{array}$ \\
\hline \multirow[t]{2}{*}{9} & \|\|$_{B}$ & $\begin{array}{l}>125 \\
>125\end{array}$ & $\begin{array}{l}>125 \\
>125\end{array}$ & $\begin{array}{l}\times 1 \\
\times 1\end{array}$ & $\begin{array}{l}3 \\
2\end{array}$ \\
\hline & ROD & $\begin{array}{l}>125 \\
>125\end{array}$ & $\begin{array}{l}>125 \\
>125\end{array}$ & $\begin{array}{l}\times 1 \\
\times 1\end{array}$ & $\begin{array}{l}2 \\
1\end{array}$ \\
\hline \multirow[t]{2}{*}{10} & \|\|$_{B}$ & $\begin{array}{l}>125 \\
>94.2\end{array}$ & $\begin{array}{l}>125 \\
=94.2\end{array}$ & $\begin{array}{l}X 1 \\
<1\end{array}$ & $\begin{array}{c}10 \\
0\end{array}$ \\
\hline & ROD & $\begin{array}{l}>125 \\
>125\end{array}$ & $\begin{array}{l}>125 \\
>125\end{array}$ & $\begin{array}{l}X 1 \\
\times 1\end{array}$ & $\begin{array}{l}4 \\
1\end{array}$ \\
\hline \multirow[t]{2}{*}{11} & $\| I_{B}$ & $\begin{array}{l}>125 \\
>118\end{array}$ & $\begin{array}{l}>125 \\
=118\end{array}$ & $\begin{array}{l}X 1 \\
<1\end{array}$ & $\begin{array}{l}7 \\
1\end{array}$ \\
\hline & ROD & $\begin{array}{l}>125 \\
>125\end{array}$ & $\begin{array}{l}>125 \\
>125\end{array}$ & $\begin{array}{l}X 1 \\
\times 1\end{array}$ & $\begin{array}{l}4 \\
0\end{array}$ \\
\hline \multirow[t]{2}{*}{12} & \|\|$_{B}$ & $\begin{array}{l}>125 \\
>125\end{array}$ & $\begin{array}{l}>125 \\
>125\end{array}$ & $\begin{array}{l}X 1 \\
X 1\end{array}$ & $\begin{array}{l}2 \\
0\end{array}$ \\
\hline & ROD & $\begin{array}{l}>125 \\
>125\end{array}$ & $\begin{array}{l}>125 \\
>125\end{array}$ & $\begin{array}{l}X 1 \\
X 1\end{array}$ & $\begin{array}{l}2 \\
0\end{array}$ \\
\hline \multirow[t]{2}{*}{13} & \|\|$_{B}$ & $\begin{array}{l}>125 \\
>121\end{array}$ & $\begin{array}{l}>125 \\
=121\end{array}$ & $\begin{array}{l}X 1 \\
<1\end{array}$ & $\begin{array}{l}4 \\
1\end{array}$ \\
\hline & ROD & $\begin{array}{l}>125 \\
>125\end{array}$ & $\begin{array}{l}>125 \\
>125\end{array}$ & $\begin{array}{l}\times 1 \\
\times 1\end{array}$ & $\begin{array}{l}7 \\
7\end{array}$ \\
\hline \multirow[t]{2}{*}{14} & \|\|$_{B}$ & $\begin{array}{l}>125 \\
>125\end{array}$ & $\begin{array}{l}>125 \\
>125\end{array}$ & $\begin{array}{l}X 1 \\
\times 1\end{array}$ & $\begin{array}{l}3 \\
0\end{array}$ \\
\hline & $\mathrm{ROD}$ & $\begin{array}{l}>125 \\
>125\end{array}$ & $\begin{array}{l}>125 \\
>125\end{array}$ & $\begin{array}{l}\times 1 \\
\times 1\end{array}$ & $\begin{array}{l}3 \\
0\end{array}$ \\
\hline \multirow[t]{2}{*}{15} & \|\|$_{B}$ & $\begin{array}{l}>125 \\
>125\end{array}$ & $\begin{array}{l}>125 \\
>125\end{array}$ & $\begin{array}{l}\times 1 \\
\times 1\end{array}$ & $\begin{array}{l}2 \\
2\end{array}$ \\
\hline & ROD & $\begin{array}{l}>125 \\
>125\end{array}$ & $\begin{array}{l}>125 \\
>125\end{array}$ & $\begin{array}{l}\times 1 \\
\times 1\end{array}$ & $\begin{array}{l}3 \\
2\end{array}$ \\
\hline \multirow[t]{2}{*}{16} & \|\|$_{B}$ & $\begin{array}{l}>111 \\
>93.9\end{array}$ & $\begin{array}{l}=111 \\
=93.9\end{array}$ & $\begin{array}{l}<1 \\
<1\end{array}$ & $\begin{array}{l}4 \\
0\end{array}$ \\
\hline & ROD & $\begin{array}{l}>125 \\
>125\end{array}$ & $\begin{array}{l}>125 \\
>125\end{array}$ & $\begin{array}{l}X 1 \\
X 1\end{array}$ & $\begin{array}{l}2 \\
1\end{array}$ \\
\hline \multirow[t]{2}{*}{17} & \|\|$_{B}$ & $\begin{array}{l}>125 \\
>121\end{array}$ & $\begin{array}{l}>125 \\
=121\end{array}$ & $\begin{array}{l}X 1 \\
<1\end{array}$ & $\begin{array}{l}7 \\
0\end{array}$ \\
\hline & ROD & $\begin{array}{l}>125 \\
>125\end{array}$ & $\begin{array}{l}>125 \\
>125\end{array}$ & $\begin{array}{l}X 1 \\
\times 1\end{array}$ & $\begin{array}{l}4 \\
3\end{array}$ \\
\hline \multirow[t]{2}{*}{18} & \|\|$_{B}$ & $\begin{array}{l}>59.2 \\
>84.8\end{array}$ & $\begin{array}{l}=59.2 \\
=84.8\end{array}$ & $\begin{array}{l}<1 \\
<1\end{array}$ & $\begin{array}{l}2 \\
0\end{array}$ \\
\hline & $\mathrm{ROD}$ & $\begin{array}{l}>72.9 \\
>80.8\end{array}$ & $\begin{array}{l}=72.9 \\
=80.8\end{array}$ & $\begin{array}{l}<1 \\
<1\end{array}$ & $\begin{array}{l}4 \\
0\end{array}$ \\
\hline
\end{tabular}


TABLE 8: Anti-HCV NS5B RdRp activity of compounds 4-18.

\begin{tabular}{cccc}
\hline Compound & \% Inhibition & Compound & \% Inhibition \\
\hline 4 & N.I. & 12 & N.I. \\
5 & N.I. & 13 & 6.4 \\
6 & N.I. & 14 & N.I. \\
7 & 12.4 & 15 & N.I. \\
8 & N.I. & 16 & N.D. \\
9 & N.I. & 17 & N.I. \\
10 & N.I. & 18 & N.I. \\
\hline
\end{tabular}

aPercent inhibition was determined at $100 \mu \mathrm{M}$ concentration of the indicated compound and represents an average of at least two independent measurements in duplicate. N.D.: not determined. N.I.: no inhibition.

$(\mathrm{m} / \mathrm{z}$ 105.0334) was determined through cleavage of amide bond of the fragment at m/z 176.1076. Except for compound 16 fragmented via quasi-molecular ion by HR-FAB, compounds 14-15, 17-18 fragmented to afford m/z 204.1019 by $\mathrm{CONH}$ - bond cleavage and 2-hydrazinylidene-3,5-dimethyl-1,3-thiazolidin-4-one moiety. The prosecuting fragmentation was observed in the same manner as compounds 9-18.

\section{Antiviral evaluation}

In view of the antiviral activity ascertained for similar 1,3-thiazolidine-4-ones, the synthesized compounds were subjected to a preliminary screening for their antiviral effects against various types of viruses in HEL, HeLa, Vero and CRFK (CrandellRees Feline Kidney) cell cultures. Compounds 4-18 were not found to be active against Feline Corona Virus (FIPV), Feline Herpes Virus, HSV-1(KOS), HSV-1(TK-KOS ACVr), HSV-2(G), Vaccinia virus, Varicella-ZosterVirus $T K^{+} V Z V$, Varicella-ZosterVirus TK-VZV, Cytomegalovirus, Vesicular stomatitis virus, Respiratory syncytial virus, Coxsackie B4 virus, Parainfluenza-3 virus,
Reovirus-1, Sindbis virus and Punta Toro virus (see Tables 3-6). Compounds 4-18 were also evaluated for their anti-HIV activity. None of the synthesized compounds showed any significant activity against HIV-1 ( $\mathrm{III}_{\mathrm{B}}$ ) or HIV-2 (strain ROD) in MT-4 cells (See Table 7) at subtoxic concentrations.

The anti-HCV activity of the compounds was also investigated employing the in vitro HCV NS5B RdRp inhibition assay as described in the experimental section. Highest inhibition against HCV NS5B RdRp activity at $100 \mu \mathrm{M}$ were observed with compounds 7 and 13 by $12.4 \%$ and $6.4 \%$, respectively. Remaining compounds exhibited no inhibition at this concentration, thus suggesting that none of the compounds specifically target HCV NS5B polymerase (see Table 8).

\section{ACKNOWLEDGEMENTS}

This work was supported by the Research Fund of Marmara University, project number: SAG-DKR-200407-0079.

\section{L-Valin yan zinciri taşıyan 1,3-tiyazolidin-4-on türevlerinin sentezi, yapılarının aydınlatılması ve antiviral etkilerinin tespiti}

ÖZET: 1,3-Tiyazolidin-4-on türevi bileşiklerin, HIV-1 non-nükleozit ters transkriptaz ve HCV NS5B RNA-bağımlı RNA polimeraz enzimlerini inhibe etmek suretiyle anti-HIV ve anti-HCV etki gösterdikleri literatürlerde bildirilmiştir. Bu bilgiden hareketle, literatürde kayıtlı olmayan 1-[2-(benzoilamino)-3-metilbutiril]-4-alkil/arilalkiltiyosemikarbazit ve 2-[2-(benzoilamino)-3- metilbutirilhidrazono]-3-alkil-/arilalkil-5-non sübstitüe / metil-1,3-tiyazolidinon türevi bileşikler sentezlenmiş ve antiviral etki potansiyeli açısından değerlendirilmişlerdir. Sentezlenen bileşikılerin antiviral etkileri; CRFK, HEL, HeLa ve Vero hücre kültürü ortamlarında çeşitli virüslere (Kedi Korona virüsü (FIPV), Kedi Herpes virüsü, HSV-1(KOS), HSV-1(TK-KOS ACVr), HSV-2(G), Vaksinya virüsü, Veziküler stomatitis virüsü, Varicella-ZosterVirüsü TK+VZV, Varicella-ZosterVirüsü TK-VZV, Sitomegalovirüs, Respiratuvar sinsitiyal virüs, Koksaki B4 virüsü, Parainfluenza-3 virüsü, Reovirüs-1, Sindbis virüsü, Punta Toro virüsü) karşı araştırılmıştır. Bileşiklerin sitotoksisitesi ve antiHIV etkileri HIV-1 (IIIB) and HIV-2 (ROD) suşlarına karşı MT-4/MTT yöntemi kullanılarak taranmış ve non-toksik dozlarda antiviral etki göstermedikleri saptanmıştır. Sentezlenen bileşikler, anti-HCV NS5B RdRp etki potansiyalleri açısından da değerlendirilmiş; ancak en yüksek derişim olan $100 \mu$ M'da HCV NS5B RdRp'a karşı inhibitör etki göstermedikleri tespit edilmiştir.

ANAHTAR SÖZCÜKLER: 4-Tiyazolidinon, L-valin, anti-HIV etki, anti-HCV etki. 


\section{REFERENCES}

1. Kline $T$, Barry KC, Jackson SR, Felise HB, Nguyen HV, Miller SI. Tethered thiazolidinone dimers as inhibitors of the bacterial type III secretion system. Bioorg Med Chem Lett 2009; 19: 1340-3.

2. Felise HB, Nguyen HV, Pfuetzner RA, Barry KC, Jackson SR, Blanc MP, Bronstein PA,Kline T, Miller SI. An inhibitor of gram-negative bacterial virulence protein secretion. Cell Host Microbe 2008; 4: 325-36.

3. Küçükgüzel G, Kocatepe A, De Clercq E, Sahin F, Güllüce M. Synthesis and biological activity of 4-thiazolidinones, thiosemicarbazides derived from diflunisal hydrazide. Eur J Med Chem 2006; 41: 353-9.

4. Puratchikody A, Natarajan R, Jayapal M, Doble M. Synthesis, in vitro antitubercular activity and 3D-QSAR of novel quinoxaline derivatives. Chem Biol Drug Des 2011; 78: 988-98.

5. Vintonyak VV, Warburg K, Kruse H, Grimme S, Hübel K, Rauh D, Waldmann H. Identification of thiazolidinones spiro-fused to indolin-2-ones as potent and selective inhibitors of the Mycobacterium tuberculosis protein tyrosine phosphatase B. Angew Chem Int Ed Engl 2010; 49: 5902-5.

6. Tatar E, Küçükgüzel İ, Küçükgüzel ŞG, Yılmaz-Demircan F, De Clercq E, Andrei G, Snoeck R, Pannecouque C, Şahin F, Bayrak ÖF. Synthesis, anti-tuberculosis and antiviral activity of novel 2-isonicotinoylhydrazono-5-arylidene4-thiazolidinones. Int J Drug Des Dis 2010; 1: 19-32.

7. Küçükgüzel SG, Oruç EE, Rollas S, Sahin F, Özbek A. Synthesis, characterisation and biological activity of novel 4-thiazolidinones, 1,3,4-oxadiazoles and some related compounds. Eur J Med Chem 2002; 37: 197-206.

8. El Bialy SA, Nagy MM, Abdel-Rahman HM.antiviral and anticancer. Efficient regioselective three-component domino synthesis of 3-(1,2,4-triazol-5-yl)-1,3-thiazolidin4-ones as potent antifungal and antituberculosis agents. Arch Pharm (Weinheim) 2011; 344: 821-9.

9. Rojas Ruiz FA, García-Sánchez RN, Estupiñan SV, Gómez-Barrio A, Torres Amado DF, Pérez-Solórzano BM, Nogal-Ruiz JJ, Martínez-Fernández AR, Kouznetsov VV. Synthesis and antimalarial activity of new heterocyclic hybrids based on chloroquine and thiazolidinone scaffolds. Bioorg Med Chem 2011; 19: 4562-73.

10. Ravichandran V, Jain A, Kumar KS, Rajak H, Agrawal RK. Design, synthesis, and evaluation of thiazolidinone derivatives as antimicrobial and anti-viral agents. Chem Biol Drug Des 2011; 78: 464-70.

11. Barreca ML, Chimirri A, De Luca L, Monforte AM, Monforte $\mathrm{P}$, Rao A, Zappalà M, Balzarini J, De Clercq E, Pannecouque C, Witvrouw $M$. Discovery of 2,3-diaryl-1,3thiazolidin-4-ones as potent anti-HIV-1 agents. Bioorg Med Chem Lett 2001; 11: 1793-6.

12. Rao A, Carbone A, Chimirri A, De Clercq E, Monforte $\mathrm{AM}$, Monforte $\mathrm{P}$, Pannecouque C, Zappalà M. Synthesis and anti-HIV activity of 2,3-diary1,3-thiazolidin-4-ones. Il Farmaco 2003; 58: 115-20.

13. Rao A, Balzarini J, Carbone A, Chimirri A, De Clercq E, Monforte AM, Monforte $\mathrm{P}$, Pannecouque $\mathrm{C}$, Zappalà M. 2-(2,6-Dihalophenyl)-3-(pyrimidin-2-yl)-1,3-thiazolidin4-ones as non-nucleoside $\mathrm{HIV}-1$ reverse transcriptase inhibitors. Antiviral Res 2004; 63: 79-84.
14. Rawal RK, Prabhakar YS, Katti SB, De Clercq E. 2-(Aryl)3-furan-2-ylmethyl-thiazolidin-4-ones as selective HIVRT inhibitors. Bioorg Med Chem 2005; 13: 6771-6.

15. Rawal RK, Tripathi $R$, Kati SB, Pannecouque $C$, De Clercq E. Design, synthesis and evaluation of 2-aryl-3-heteroaryl-1,3-thiazolidin-4-ones as anti-HIV agents. Bioorg Med Chem 2007; 15: 1725-31.

16. Rawal RK, Kumar A, Siddiqi MI, Katti SB. Molecular docking studies on 4-thiazolidinones as HIV-1 RT inhibitors. J Mol Model 2007; 13: 155-61.

17. Rawal RK, Tripathi $R$, Katti SB, Pannecouque $C$, De Clercq E. Design and synthesis of 2-(2,6-dibromophenyl)3-heteroaryl-1,3-thiazolidin-4-ones as anti-HIV agents. Eur J Med Chem 2008; 43: 2800-6.

18. Chen $H$, Bai J, Jiao L, Guo Z, Yin Q, Li X. Design, microwave-assisted synthesis and HIV-RT inhibitory activity of 2-(2,6-dihalophenyl)-3-(4,6-dimethyl-5-(un)substituted-pyrimidin-2-yl)thiazolidin-4-ones. Bioorg Med Chem 2009; 17: 3980-6.

19. Balzarini J, Orzeszko-Krzesińska B, Maurin JK, Orzeszko A. Synthesis and anti-HIV studies of 2- and 3-adamantyl-substituted thiazolidin-4-ones. Eur J Med Chem 2009; 44: 303-11.

20. Kaushik-Basu N, Bopda-Waffo A, Talele TT, Basu A, Chen Y, Kucukguzel SG. 4-Thiazolidinones: a novel class of hepatitis C virus NS5B polymerase inhibitors. Front Biosci 2008; 13: 3857-68.

21. Rawal RK, Kati SB, Kaushik-Basu N, Arora P, Pan Z. Non-nucleoside inhibitors of the hepatitis $C$ virus NS5B RNA-dependent RNA polymerase : 2-Aryl-3-heteroaryl-1,3-thiazolidin-4-one derivatives. Bioorg Med Chem Lett 2008; 18: 6110-4.

22. Lemm JA, O'Boyle DR, Liu M, Nower PT, Colonno R, Deshpande MS, Snyder LB, Martin SW, St Laurent DR, Serrano-Wu MH, Romine JL, Meanwell NA, Gao M. Identification of hepatitis C virus NS5A inhibitors. J Virol 2010; 84: 482-91.

23. Lemm JA, Leet JE, $\mathrm{O}^{\prime}$ Boyle DR, Romine JL, Huang XS, Schroeder DR, Alberts J, Cantone JL, Sun JH, Nower PT, Martin SW, Serrano-Wu MH, Meanwell NA, Snyder LB, Gao M. Discovery of potent hepatitis C virus NS5A inhibitors with dimeric structures. Antimicrob Agents Chemtherap 2011; 55: 3795-802.

24. Keller TH, Shi PY, Wang QY. Anti-infectives: can cellular screening deliver? Curr Opin Chem Biol 2011; 15: 529-33.

25. Chen $X$, Zhan $P$, Pannecouque C, Balzarini J, De Clercq E, Liu X. Synthesis and biological evaluation of piperidinesubstituted triazine derivatives as HIV-1 non-nucleoside reverse transcriptase inhibitors. Eur J Med Chem 2012; 51:60-6.

26. De Clercq E. Anti-HIV drugs: 25 compounds approved within 25 years after the discovery of HIV. Int J Antimicrob Agents 2009; 33: 307-20.

27. Camarasa MJ, Velázquez $S$, San-Félix A, Pérez-Pérez MJ, Gago F. Dimerization inhibitors of HIV-1 reverse transcriptase, protease and integrase: a single mode of inhibition for the three HIV enzymes. Antiviral Res 2006; 71: 260-7.

28. De Clercq E. A 40-year journey in search of selective antiviral chemotherapy. Annu Rev Pharmacol Toxicol 2011; 51: 1-24. 
29. Barreca ML, Rao A, De Luca L, Zappalà $M$, Monforte AM, Maga G, Pannecouque C, Balzarini J, De Clercq E, Chimirri A, Monforte P. Computational strategies in discovering novel non-nucleoside inhibitors of HIV-1 RT. J Med Chem 2005; 48: 3433-7.

30. Menéndez-Arias L, Betancor G, Matamoros T. HIV-1 reverse transcriptase connection subdomain mutations involved in resistance to approved non-nucleoside inhibitors. Antiviral Res 2011; 92: 139-49.

31. Mao Y, Li Y, Hao M, Zhang S, Ai C. Docking, molecular dynamics and quantitative structure-activity relationship studies for HEPTs and DABOs as HIV-1 reverse transcriptase inhibitors. J Mol Model 2012; 18: 2185-98.

32. Tatar E, Küçükgüzel İ, De Clercq E. 3-[2-(Arylamino)3-methylbutanamido]-2-aryl-5-substituted/non-substituted-1,3-thiazolidine-4-ones as antiviral agents. 5th International Symposium on Pharmaceutical Chemistry, September 5-7, 2007, İstanbul, Turkey, Published in: Turkish Journal of Pharmaceutical Sciences, Special Issue, 2007.

33. Tatar E, Küçükgüzel İ, De Clercq E. Synthesis, characterisation and antiviral activity of novel 1,3-thiazolidine-4-ones derived from new 1-[2-(benzoylamino)-3metylbutyryl]-4-alkyl/arylalkyl thiosemicarbazides. 5th International Symposium on Pharmaceutical Chemistry, September 5-7, 2007, İstanbul, Turkey, Published in: Turkish Journal of Pharmaceutical Sciences, Special Issue, 2007.

34. Küçükgüzel İ, Tatar E, Küçükgüzel ŞG, Rollas $S$, De Clercq E. Synthesis of some novel thiourea derivatives obtained from 5-[(4-aminophenoxy)methyl]-4-alkyl/ aryl-2,4-dihydro-3H-1,2,4-triazole-3-thiones and evaluation as antiviral/anti-HIV and anti-tuberculosis agents. Eur J Med Chem 2008; 43: 381-92.

35. Tatar E, Küçükgüzel İ, De Clercq E, Şahin F, Güllüce M. Synthesis, characterization and screening of antimicrobial, antituberculosis, antiviral and anticancer activity of novel 1,3-thiazolidine-4-ones derived from 1-[2-(benzoylamino)-4-(methylthio)butyryl]-4-alkyl/ arylalkyl thiosemicarbazides. Arkivoc 2008; 14: 191-210.

36. Giret MT, Kallas EG. GBV-C: state of the art and future prospects. Curr HIV/AIDS Rep 2012; 9: 26-33.

37. Grebely J, Tyndall MW. Management of HCV and HIV infections among people who inject drugs. Curr Opin HIV AIDS 2011; 6: 501-7.

38. Barnabas RV, Webb EL, Weiss HA, Wasserheit JN. The role of coinfections in HIV epidemic trajectory and positive prevention: a systematic review and meta-analysis. AIDS 2011; 25: 1559-73.

39. Karrer $P$, Van der Sluys VFC. The configuration of natural valine. Helv Chim Acta 1932; 15: 746-50.

40. Applewhite $\mathrm{TH}$, White $H$, Niemann C. a-Chymotrypsincatalysed hydrolysis of acetyl-, chloroacetyl-, and benzoyl-L-valine methyl ester. J Am Chem Soc 1958; 80: 1465-9.
41. Slebioda M, St-Amand MA, Chen FMF, Benoiton NL. Studies on the kinetics of racemization of 2,4-disubstituted-5(4H)- oxazolones. Can J Chem 1988; 66: 2540-4.

42. Pauwels R, Balzarini J, Baba M, Snoeck R, Schols D, Herdewijn P. Rapid and automated tetrazolium-based colorimetric assay for the detection of anti-HIV compounds. J Virol Methods 1988; 20: 309-21.

43. Popovic M, Sarngadharan MG, Read E, Gallo RC. Detection, isolation, and continuous production of cytopathic retroviruses (HTLV-III) from patients with AIDS and pre-AIDS, Science 1984; 224: 497-500.

44. Barré-Sinoussi $F$, Chermann JC, Nugeyre MT, Chamaret S, Grest J, Dauget C, Axler-Blin C, Vézinet-Brun F, Rouzioux C, Rozenbaum W, Montagnier L. Isolation of a T-lymphotropic retrovirus from a patient at risk for acquired immune deficiency syndrome (AIDS). Science 1983; 220: 868-71.

45. Miyoshi I, Taguchi H, Kobonishi I, Yoshimoto S, Ohtsuki Y, Shiraishi Y, Akagi T. TypeC-virus-producing cell lines derived from adult T cell leukaemia. Gann Monogr 1982; 28: 219-28.

46. De Clercq E, Descamps J, Verhelst G, Walker RT, Jones AS, Torrence PF, Shugar D. Comparative efficacy of antiherpes drugs against different strains of herpes simplex virus. J Infect Dis 1980; 141: 563-74.

47. De Clercq E. Antiviral and antimetabolic activities of neplanocins. Antimicrob Agents Chemother 1985; 28: 84-9.

48. De Clercq E, Holý A, Rosenberg I, Sakuma T, Balzarini J, Maudgal P. A novel selective broad-spectrum anti-DNA virus agent. Nature 1986; 323: 464-7.

49. Kaushik-Basu N, Bopda-Waffo A, Talele TT, Basu A, Costa PR, da Silva AJ, Sarafianos, SG, Noel F. Identification and characterization of coumestans as novel HCV NS5B polymerase inhibitors. Nucleic Acids Res 2008; 36: 1482-96.

50. Archana, Srivastava VK, Kumar A. Synthesis of newer thiadiazolyl and thiazolidinonyl quinazolin-4 $(3 \mathrm{H})$-ones as potential anticonvulsant agents. Eur J Med Chem 2002; 37: 873-82.

51. Wrobel J, Jetter J, Kao W, Rogers J, Di L, Chi J, Peréz MC, Chen GC, Shen ES. 5-Alkylated thiazolidinones as follicle-stimulating hormone (FSH) receptor agonists. Bioorg Med Chem 2006; 14: 5729-41.

52. Rehse $K$, Lüdtke E. $Z / E$ Isomerism in Thiazole- and 1,3,4-Thiadiazole-2-nitrosimines. Arch Pharm (Weinheim) 1992; 327: 647-51.

53. Çapan G, Ulusoy $N$, Ergenç N, Kiraz M. New 6-phenylimidazo[2,1-b]thiazole derivatives: Synthesis and antifungal activity. Monatsh Chem 1999; 130: 1399407.

54. Marković R, Baranac M, Juranić $N$, Macura $S$, Cekić I, Minić D. 1H-NMR Dynamic study of thermal Z/E isomerization of 5-substituted 2-alkylidene-4-oxothiazolidine derivatives: Barriers to rotation about $\mathrm{C}=\mathrm{C}$ bond. $\mathrm{J}$ Mol Struc 2006; 800: 85-92. 